Keywords: HB-Line, AFS-2, Purification, Anion Exchange, Specification, $M O X$

Retention: Permanent

\title{
HB-Line Anion Exchange Purification of AFS-2 Plutonium for MOX
}

\author{
E. A. Kyser \\ W. D. King
}

April 2012

Savannah River National Laboratory Savannah River Nuclear Solutions Aiken, SC 29808

Prepared for the U.S. Department of Energy under contract number DE-AC09-08SR22470. 


\section{DISCLAIMER}

This work was prepared under an agreement with and funded by the U.S. Government. Neither the U.S. Government or its employees, nor any of its contractors, subcontractors or their employees, makes any express or implied:

1. warranty or assumes any legal liability for the accuracy, completeness, or for the use or results of such use of any information, product, or process disclosed; or

2. representation that such use or results of such use would not infringe privately owned rights; or

3. endorsement or recommendation of any specifically identified commercial product, process, or service.

Any views and opinions of authors expressed in this work do not necessarily state or reflect those of the United States Government, or its contractors, or subcontractors.

\section{Printed in the United States of America}

Prepared for U.S. Department of Energy 


\section{AUTHORS:}

original approved by E. A. Kyser

$4 / 25 / 2012$

E. A. Kyser

Date

Separations and Actinide Science Programs

original approved by W. D. King

$4 / 25 / 2012$

W. D. King

Date

Advanced Characterization and Process

TECHNICAL REVIEW:

original approved by C. A. Nash 4/25/2012

C. A. Nash Date

Advanced Characterization and Process

original approved by T. S. Rudisill 4/24/2012

T. S. Rudisill Date

Separations and Actinide Science Programs

original approved by A. E. Visser $\quad$ 4/25/2012

A. E. Visser Date

Separations and Actinide Science Programs

APPROVAL:

original approved by S.D. Fink 4/25/2012

S. D. Fink, Manager Date

Separations and Actinide Science Programs

original approved by S. L. Marra 4 4/25/2012

S. L. Marra, Manager Date

Environmental \& Chemical Process Technology Research Programs

original approved by K.P. Burrows $\quad$ 4/25/2012

K. P. Burrows, Manager Date

HB-Line Engineering 


\section{Table of Contents}

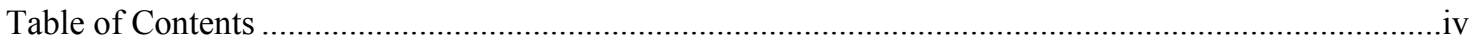

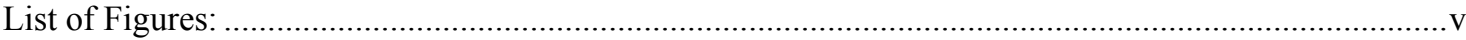

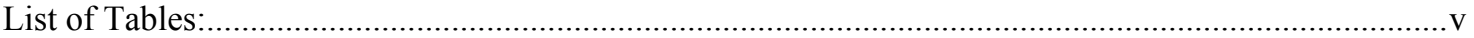

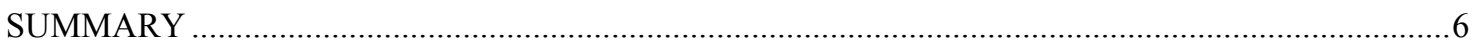

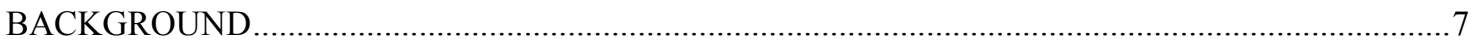

Significant Impurities in AFS-2 Feedstocks:.................................................................... 7

Process Impurities and Impurity Removal by Anion Exchange: ............................................

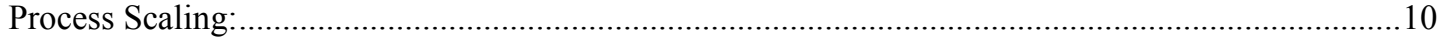

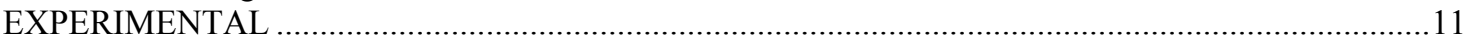

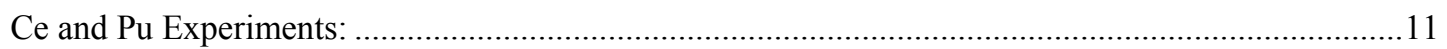

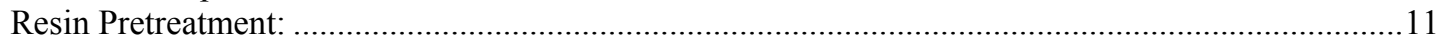

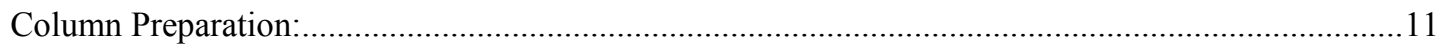

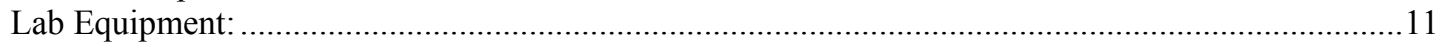

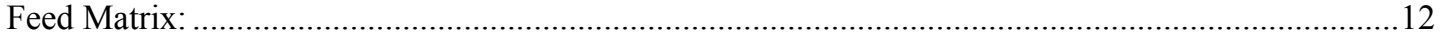

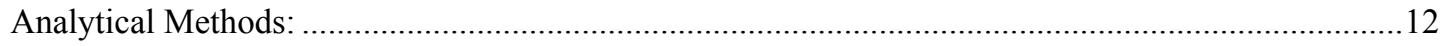

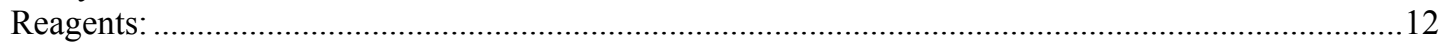

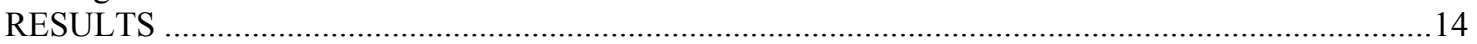

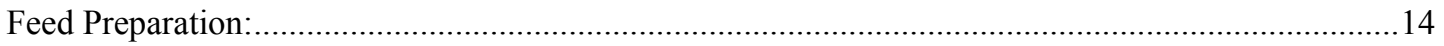

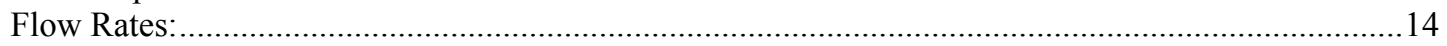

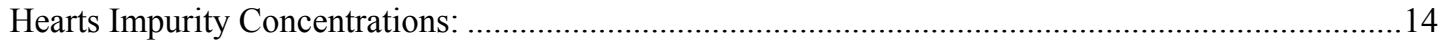

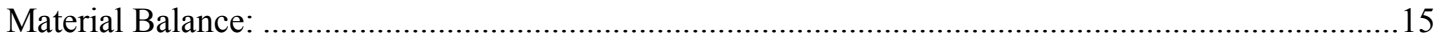

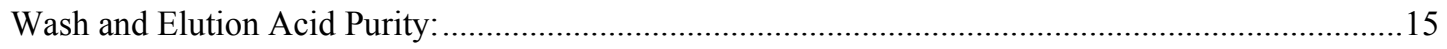

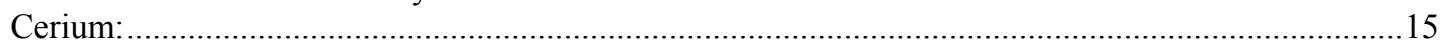

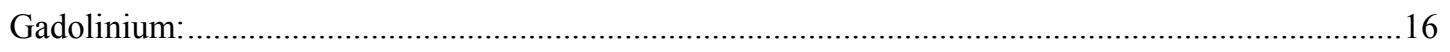

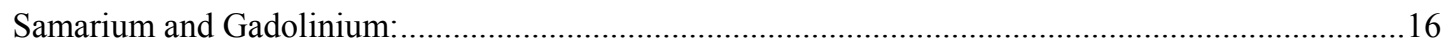

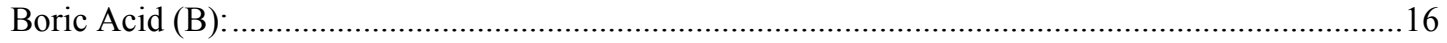

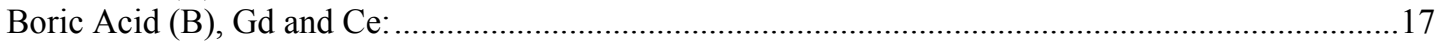

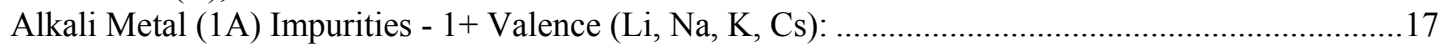

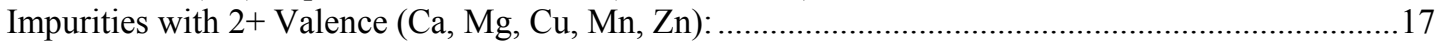

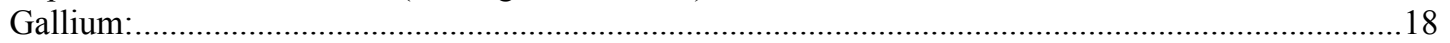

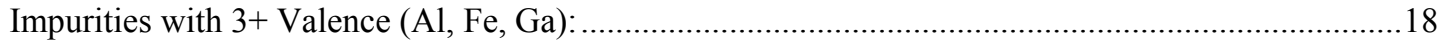

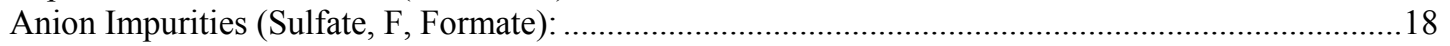

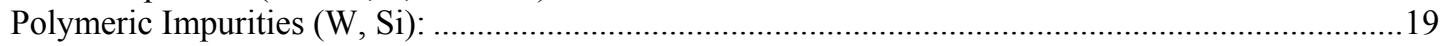

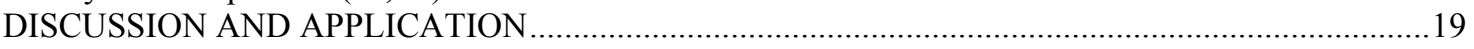

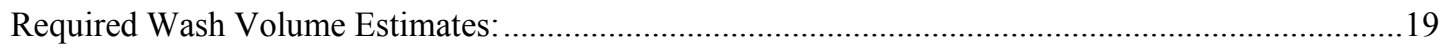

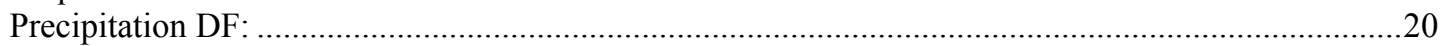

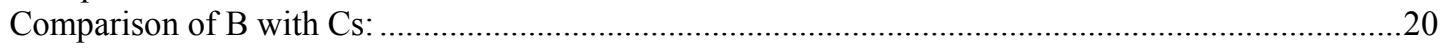

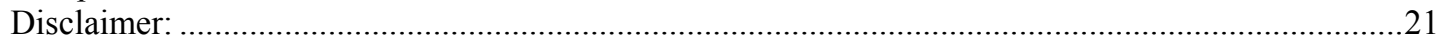

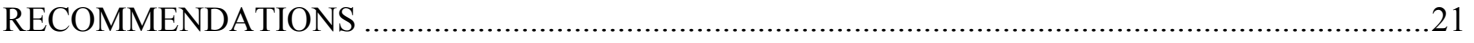

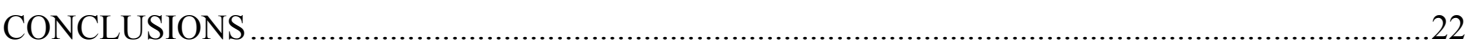

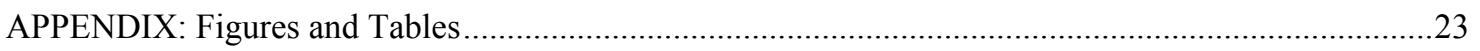




\section{List of Figures:}

Figure 1. Distribution Coefficients in a Nitrate Anion Exchange System with Expected Impurities in HB-Line Process.

Figure 2a. Assembled Column for Non-Radioactive DF Experiments. ......................... 27

Figure 2b Screen used to Retain Resin Bed. ...................................................... 27

Figure 3. Assembled Column for Glovebox DF Experiments. . ................................... 28

Figure 4. Up-flow Load/Wash Experimental Setup. ......................................... 29

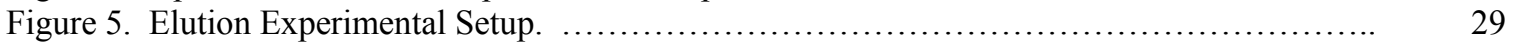

Figure 6. $\mathrm{Ce}, \mathrm{Pu}$, and Am Wash-Elution Profile. ............................................ 40

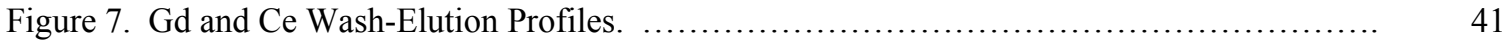

Figure 8. Sm, Gd, and Ce Wash-Elution Profiles. ......................................... 42

Figure 9. B and Ce Wash-Elution Profiles. ....................................................... 43

Figure 10. B, Gd, and Ce Wash-Elution Profiles. ............................................ 44

Figure 11. $\mathrm{Li}, \mathrm{Na}, \mathrm{K}, \mathrm{Cs}, \mathrm{Ce}, \mathrm{Pu}$, and Am Wash-Elution Profiles. ................................ 45

Figure 12. $\mathrm{Ca}, \mathrm{Cu}, \mathrm{Mg}, \mathrm{Mn}, \mathrm{Zn}, \mathrm{Ce}, \mathrm{Pu}$, and $\mathrm{Am}$ Wash-Elution Profiles. .......................... 46

Figure 13. $\mathrm{Ga}, \mathrm{Ce}, \mathrm{Pu}$, and Am Wash-Elution Profiles. ........................................ 47

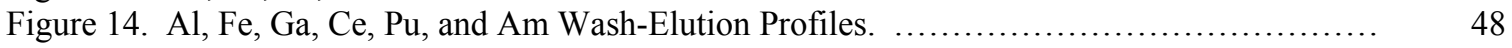

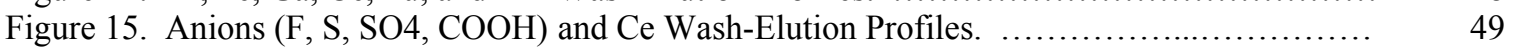

Figure 16. Si, W, and Ce Wash-Elution Profiles. ................................................. 50

Figure 17. B, Al, Cs, Mn, Gd, Fe, Am, and Pu Wash-Elution Profiles. .......................... 51

\section{List of Tables:}

Table 1. Draft $\mathrm{PuO}_{2}$ Specification Limits. ................................................ 24

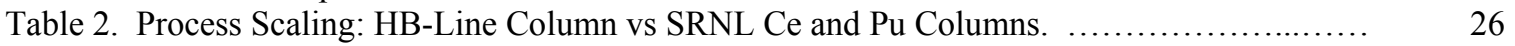

Table 3. Proposed Impurities for Anion Exchange Testing. ................................... 30

Table 4. Feed Preparation for $\mathrm{Cr} 310, \mathrm{Cr} 311, \mathrm{Cr} 313$ and $\mathrm{Cr} 314$ Experiments. ....................... 31

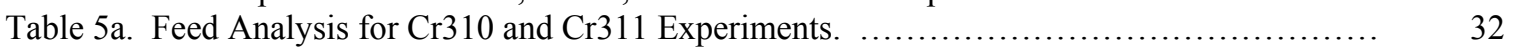

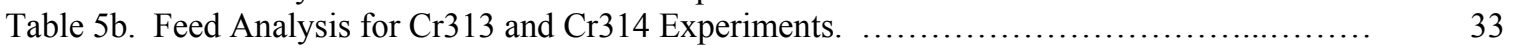

Table 6. Targeted and Actual Flowrates. ................................................. 34

Table 7. Analyzed Impurity Concentrations in Hearts Samples. ............................. 35

Table 8a. Impurity Material Balance for Cr310, Cr311 and Cr314 Column Runs. ................ 36

Table 8b. Material Balance for Pu Column Experiment Cr313 (85cc Two Piece Column Reillex $\left.\mathrm{HPQ}^{\mathrm{TM}}\right)$.

Table 8c. Material Balance for Pu Column Experiment Cr314 (85cc Two Piece Column Reillex

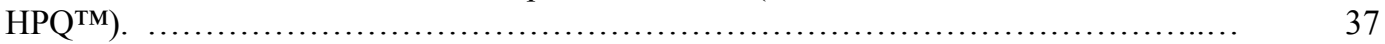

Table 9. Anion Exchange DF Observations. .......................................... 38

Table 10. Minimum Wash Volumes to Achieve Column A Specification. ........................ 51

Table 11. Minimum Wash Volumes to Achieve Column B Specification. ........................ 52 


\section{HB-Line Anion Exchange Purification of AFS-2 Plutonium for MOX}

\section{SUMMARY}

Non-radioactive cerium $(\mathrm{Ce})$ and radioactive plutonium $(\mathrm{Pu})$ anion exchange column experiments using scaled HB-Line designs were performed to investigate the feasibility of using either gadolinium nitrate $(\mathrm{Gd})$ or boric acid ( $\mathrm{B}$ as $\left.\mathrm{H}_{3} \mathrm{BO}_{3}\right)$ as a neutron poison in the $\mathrm{H}$-Canyon dissolution process. Expected typical concentrations of probable impurities were tested and the removal of these impurities by a decontamination wash was measured. Impurity concentrations are compared to two specifications - designated as Column A or Column B (most restrictive) - proposed for plutonium oxide $\left(\mathrm{PuO}_{2}\right)$ product shipped to the Mixed Oxide (MOX) Fuel Fabrication Facility (MFFF).

Use of Gd as a neutron poison requires a larger volume of wash for the proposed Column A specification. Since boron (B) has a higher proposed specification and is more easily removed by washing, it appears to be the better candidate for use in the H-Canyon dissolution process. Some difficulty was observed in achieving the Column A specification due to the limited effectiveness that the wash step has in removing the residual B after $\sim 4$ BV's wash. However a combination of the experimental 10 BV's wash results and a calculated DF from the oxalate precipitation process yields an overall DF sufficient to meet the Column A specification. For those impurities (other than B) not removed by 10 BV's of wash, the impurity is either not expected to be present in the feedstock or process, or recommendations have been provided for improvement in the analytical detection/method or validation of calculated results. In summary, boron is recommended as the appropriate neutron poison for $\mathrm{H}$ Canyon dissolution and impurities are expected to meet the Column A specification limits for oxide production in HB-Line. 


\section{BACKGROUND}

HB-Line Engineering requested that SRNL develop an anion exchange flowsheet ${ }^{1}$ for the purification of $\mathrm{Pu}$ dissolved in H-Canyon to meet the proposed Interface Control Document (ICD) limits ${ }^{2}$ for the Mixed Oxide MOX Fuel Fabrication Facility (MFFF) (see Table 1). Three levels of ICD limits are given: 1) Column B, 2) Column A and 3) Exceptional. Significant levels of select impurities will be added in the $\mathrm{H}$-Canyon dissolution process ${ }^{3}$ but additional information was needed to determine what other impurities need to be removed by the process. The proposed feedstock to this process is part of an inventory characterized as Alternate Feedstocks 2 (AFS-2) and consists of Pu metal from multiple sources.

The major impurities expected in the feed to HB-Line are primarily those added during the dissolution process in $\mathrm{H}$-Canyon (i.e., Gd or B, potassium (K), fluoride $(\mathrm{F})$, and aluminum (Al)). Gallium $(\mathrm{Ga})$ is also a major impurity as it comprises a significant component in the AFS-2 feedstock. After the $\mathrm{Pu}$ metal is dissolved in H-Canyon, HB-Line will perform anion exchange, oxalate precipitation, filtration and calcination to produce a plutonium dioxide $\left(\mathrm{PuO}_{2}\right)$ product. The primary purification will be performed by anion exchange but additional purification will be obtained by precipitation, filtration and calcination for some impurities.

This report documents ion exchange column experiments aimed at determining the differences between the two potential neutron poisons and determining an appropriate wash volume to remove the poison and other impurities to meet the Column A specifications from the draft ICD.

Significant Impurities in AFS-2 Feedstocks: $\mathrm{Kyser}^{4}$ previously performed an evaluation of the potential impurities that could be present in AFS-2 feedstocks. Impurity data for AFS-2 metal from three primary sources was evaluated: 1) cast and uncast metal, 2) pit parts and 3) SRS button data. Studies by Allender ${ }^{5}$ and Moore ${ }^{6,7}$ documented the expected impurity content of cast and uncast metals which constitute a significant fraction of the AFS-2 feedstocks and identified iron (Fe), nickel $(\mathrm{Ni})$, chromium $(\mathrm{Cr})$ and tungsten $(\mathrm{W})$ as impurities that could significantly exceed the MOX acceptance limits being considered at that time. Not all elements in Table 1 were routinely reported in Rocky Flats production reports which were the primary source of the analyses cited in reference 5. Rocky Flats had not identified a credible source for other elements to be present above $100 \mathrm{ppm}$. Of the elements measured, Ga was found to be consistently high relative to the Column A and Exceptional specifications. The following elements showed occasional high values relative to the Column A specification: $\mathrm{Al}$, calcium $(\mathrm{Ca}), \mathrm{Fe}, \mathrm{K}$, lithium ( $\mathrm{Li})$, magnesium $(\mathrm{Mg})$, molybdenum (Mo), sodium $(\mathrm{Na}), \mathrm{Ni}, \mathrm{W}$, and zinc $(\mathrm{Zn})$. Some occasional high values may be due to reporting errors but this can-

\footnotetext{
${ }^{1}$ J. W. Christopher, "Flowsheet Development for HB-Line Phase II Oxide Production," NMMD-HTS-20113177, Revision 0 (Nov 10, 2011).

${ }^{2}$ MFFF - H-Area/K-Area Plutonium Dioxide Powder Interface Control Document, ICD-11-032-01, G-ESR-H00189, Rev. 0d DRAFT, 11/1/2011.

${ }^{3}$ T. S. Rudisill, R. A. Pierce, "Dissolution of Plutonium Metal in 8-10 M Nitric Acid", SRNL-STI-2012-00043, Savannah River National Laboratory, Aiken SC, February, 2012.

${ }^{4}$ E. A. Kyser, "Impurities for Anion Exchange Testing - Pu to MOX", SRNL-L3100-2011-00234, Savannah River National Laboratory, Aiken SC, December 16, 2011.

5 J. S. Allender "Preliminary Chemical Analysis of AFS-2 Candidate Metal Items", SRNL-TR-2011-00333, Savannah River National Laboratory, Aiken SC, November 18, 2011.

${ }^{6}$ E. N. Moore, "Potential Corrosion Product Pickup in AFS-2 and Pit Feeds", SRNS-RP-2011-00106, Moore Nuclear Energy, LLC, Aiken, SC, January 18, 2011.

${ }^{7}$ E. N. Moore, "Addendum for Potential Corrosion Product Pick-up in AFS-2 and Pit Feeds,"SRNS-RP-201101033, Moore Nuclear Energy, LLC, Aiken, SC, April 28, 2011.
} 
not be confirmed (e.g., W is suspect). For the actinide elements (uranium (U), neptunium (Np), and americium (Am)) and for the common elements in salts used in pyrochemistry ( $\mathrm{Li}, \mathrm{K}, \mathrm{Ca}, \mathrm{Na}, \mathrm{Mg}$, chloride $(\mathrm{Cl})$, and $\mathrm{F}$ ) the absence of data was not a reliable indication for the lack of this impurity. However for other less common elements, the lack of data was assumed to indicate a relative absence of the given impurity in the AFS-2 feedstock. There are several rare earth elements (samarium (Sm), dysprosium (Dy), and europium (Eu)) which have low limits due to their neutron absorption characteristics. Estimation of the impurity levels for $\mathrm{Sm}, \mathrm{Dy}$, and $\mathrm{Eu}$ in $\mathrm{Pu}$ oxide at concentrations of $\sim 2$ $\mu \mathrm{g} / \mathrm{g} \mathrm{Pu}^{8}$ was discussed by Moore et al. Similarly, Cd was estimated to be present in average concentrations of 13-17 $\mu \mathrm{g} / \mathrm{g} \mathrm{Pu}$. It is assumed that lack of these impurities in Pu oxide is sufficient evidence that they will not be present in AFS-2 metal. Since these impurities (Cd, Sm, Dy, and Eu) appear to not exist in greater than minor amounts, their concentration will be insignificant compared to the concentration of Gd which may be used in the process.

Process Impurities and Impurity Removal by Anion Exchange: $\mathrm{James}^{9}$ and $\mathrm{Marsh}^{10}$ each provide a periodic table viewpoint on the affinity of various elements for a nitrate anion exchange system. Each author interpreted the data available to them in a different fashion. Modified versions of the periodic table from James and Marsh are included as Figure 1 with color coding to show the expected and potential process impurities that have been identified. Note that none of the major impurities identified in the AFS-2 feed show significant affinity for the resin. James indicates that the rare earths have a slight affinity for anion resin and, although he does not provide a distribution value, Gd likely behaves similarly to the other $3+$ valence rare earths. Marsh indicates that Gd, B and most of the rare earths do not have any affinity for anion resin. It is not apparent which data is more applicable to the current process. With the low specification limits, both $\mathrm{Gd}$ and B were tested and are expected to be the limiting impurities in the development of the flowsheet. Any of the rare earth impurities ( $\mathrm{Sm}, \mathrm{Dy}, \mathrm{Eu})$ at low concentrations should be removed by the washing step to remove $\mathrm{Gd}$ and it is concluded that these did not pose any additional concerns for flowsheet development.

Most impurities identified (major impurities: $\mathrm{K}, \mathrm{Al}, \mathrm{Ga}$, and $\mathrm{Fe}$ as well as minor/potential impurities: $\mathrm{Li}, \mathrm{Na}, \mathrm{Mg}, \mathrm{Ca}, \mathrm{Ti}, \mathrm{Cr}^{+3}, \mathrm{Ni}$, and $\mathrm{Cu}$ ) appear to have no affinity for anion resin and should be easily removed. A representative subset was chosen for testing which included all the major impurities and a subset of the minor impurities $(\mathrm{Na}, \mathrm{Mg}, \mathrm{Ca}$, and $\mathrm{Cu}) . \mathrm{Cr}$ and $\mathrm{Ni}$ were not tested since HB-Line has demonstrated during the recent $\mathrm{Np}$ campaign ${ }^{11,12,13}$ an anion exchange DF of $700 \mathrm{for} \mathrm{Cr}$ and 400 for $\mathrm{Ni}$ for $\sim 8$ bed volumes of decontamination wash which should provide a reasonable basis for the expected DF for these corrosion impurities.

There is a short list of anions $\left(\mathrm{F}, \mathrm{Cl}\right.$, and $\mathrm{SO}_{4}{ }^{-2}$ ) potentially present in solution that may have some affinity to the resin. Testing of the $\mathrm{F}$ anion complexed with 2:1 molar ratio of $\mathrm{Al}$ was performed but the IC Anion solution analysis is recognized as unable to measure either $\mathrm{F}$ or $\mathrm{Cl}$ at the specification

\footnotetext{
${ }^{8}$ E. Moore, R. Saylor, J. Allender, S. Davies, "Chemical Impurities in Candidate Alternate Feedstock Oxides for the MOX Fuel Fabrication Facility- 2006 Analysis Update", SVP-OPD-2006-00003, Washington Savannah River Co, Aiken, SC July 31, 2006.

${ }^{9}$ D. B. James, “Anion Exchange Processing of Plutonium”, LA-3499, Los Alamos Scientific Laboratory, Los Alamos, NM, January 4, 1966.

${ }^{10}$ S. F. Marsh, "Evaluation of a New Macroporous Polyvinylpyridine Resin for Processing Plutonium Using Nitrate Anion Exchange", LA-11490, Los Alamos National Laboratory, Los Alamos, NM (April 1989).

${ }^{11}$ E. A. Kyser, "Np SME Memo", email comments to L. Sims, January 15, 2008.

${ }^{12}$ A. M. Murray, R. W. Watkins, "Np SME Team Review of HB-Line NT-21/NT-22 Solution Results", SRNLATS-2008-00006, Savannah River National Laboratory, January 15, 2008.

${ }^{13}$ A. M. Murray, R. W. Watkins, "Np SME Team Review of H-Canyon Tank 9.5 Solution Results", SRNLATS-2007-00050, Savannah River National Laboratory, August 1, 2007.
} 
limit. It is assumed that the amount of $\mathrm{Cl}$ is relatively minor compared with the amount $\mathrm{F}$ used in the flowsheet and therefore $\mathrm{Cl}$ was not tested. Although ferrous sulfamate $\left(\mathrm{FS}, \mathrm{Fe}\left(\mathrm{NH}_{2} \mathrm{SO}_{3}\right)_{2}\right)$ is not planned to be used in the HB-Line process for valence adjustment, it was required in the Pu laboratory tests due to the use of recycled $\mathrm{Pu}$ solutions and was also tested in the non-radioactive Ce experiments. The actual amount of sulfate vs. sulfamate is not known to sufficient accuracy to measure a true DF. This limitation should not have much impact because no sulfamate or sulfate is planned for use in the production process but does complicate interpretation of the limited $\mathrm{S}$ data obtained. To mitigate the limited analytical capability for $\mathrm{F}$ and $\mathrm{Cl}$ in solution, a precipitation study will be performed later using $\mathrm{Pu}$ washed sufficiently to remove the neutron poison ( $\mathrm{Gd}$ or $\mathrm{B}$ ). The Pu product solution will be oxalate precipitated in a series of tests with varying amounts of $\mathrm{HF}$ and $\mathrm{HCl}$ added (using the standard addition method). The product from each precipitation will be filtered, washed and then calcined to $\sim 650{ }^{\circ} \mathrm{C}$. It is believed that each of these steps will remove some $\mathrm{F}$ or $\mathrm{Cl}$ impurity. Both $\mathrm{HF}$ and $\mathrm{HCl}$ (simultaneously) will be tested in precipitation/calcination and the calcined oxide product will be analyzed to determine the DF for these anions. F/H Area Laboratories can perform a pyrohydrolysis analysis for $\mathrm{F}$ and $\mathrm{Cl}$ with a $20 \mu \mathrm{g} / \mathrm{g}$ Pu detection limit which should be sufficient to determine a $\mathrm{F}+\mathrm{Cl}$ concentration $<250 \mu \mathrm{g} / \mathrm{g} \mathrm{Pu}$.

There is a short list of transition metal impurities $\left(\mathrm{W}, \mathrm{Mo}, \mathrm{Cr}^{6+}\right.$, and $\mathrm{Bi}^{3+}$ ) that may be present in solution as anions that may have some affinity to the resin. Tungsten and Mo exist as tungstic and molybdic acids and have limited solubility in $8 \mathrm{M} \mathrm{HNO}_{3}$ acid solution. Tungsten and Mo also may be present in high concentrations in a limited number of AFS-2 items. Testing the anion exchange DF was not practical due to the solubility limitations. In the production process, minor amounts of solids that are left after dissolution as well as any post-dissolution solids that could form may be transferred to the anion exchange process. Filters on the feed stream to anion exchange will remove large solids but might not remove fine solids, although the ion exchange columns may well trap any fine solids present. Insufficient information is currently known about W and Mo to completely address their behavior in the process at this time but simple testing as an anion exchange impurity is also not likely to be successful. Feedstocks that involve significant quantities of these transition metal impurities (W, $\mathrm{Mo}, \mathrm{Cr}^{6+}$, and $\mathrm{Bi}^{3+}$ ) should be avoided unless additional testing is performed.

Any $\mathrm{Cr}$ that might exist as $\mathrm{Cr}^{6+}$ would have some affinity for anion resin; however, $\mathrm{Cr}^{6+}$ is not stable thermodynamically in the low $\mathrm{pH}$ of the feed solutions so $\mathrm{Cr}$ is expected to exist in the $\mathrm{Cr}^{3+}$ valence state. Confirmation of the absence of significant $\mathrm{Cr}^{6+}$ under realistic process conditions is desired. HB-Line has recent data from the Np campaign ${ }^{11,12,13}$ that indicates a DF of 700 for Cr (likely as $\left.\mathrm{Cr}^{3+}\right)$ in that process.

Bismuth also may exist as an anionic species in solution. If present it would be expected to have an affinity for anion resin similar to U. Data for Bi is not available for AFS-2 feedstocks; however the report by $\mathrm{Moore}^{8}$ on $\mathrm{Pu}$ oxides gives average Bi concentrations of $117 \mu \mathrm{g} / \mathrm{g} \mathrm{Pu}$. Based on the this low value of $\mathrm{Bi}$ impurity in the $\mathrm{Pu}$ oxide, $\mathrm{Bi}$ was not tested as very limited $\mathrm{DF}$ would be required to make the column A specification. Bi also probably has solubility limitations similar to $\mathrm{W}$ and Mo. Any soluble Bi present should behave similarly to U. Uranium and Bi absorb somewhat more than most impurities onto anion resin and will require extensive washing to remove significant amounts. During the recent HB-Line Np campaign ${ }^{11,12,13} \sim 8$ bed volumes of wash was used to realize a DF of $\sim 500$ for $\mathrm{U}$; however, a DF of only $\sim 15$ was observed for $\mathrm{Ce}$ (which is reported as more weakly retained).

The limits for $\mathrm{N}$ and $\mathrm{C}$ are driven by the concern for difficult to dissolve nitrides, carbides and graphite. Such materials will not be soluble in the H-Canyon dissolution process and any solids of significant size will plug process filters in HB-Line if they are transferred to that point in the process and will not make it to the precipitation process step. Therefore, no effort was made to measure for these 
materials in this flowsheet development effort. (A parallel study on precipitation ${ }^{14}$ will measure the concentration of $\mathrm{C}$ as residual oxalate in the product.)

The Marsh and James references agree that vanadium (V) and indium (In) do not absorb onto anion resin. Thorium (Th) and $\mathrm{Np}$ absorb strongly onto anion resin and it is not reasonable to develop an anion exchange flowsheet to remove these elements if the amounts are significant. Blending to achieve specifications or performing solvent extraction separation would be reasonable alternatives.

The validity of this evaluation and the proposed testing depends on the speciation being consistent between the literature references, the proposed laboratory tests and the eventual plant process. Every effort needs to be made to avoid conditions where the speciation of the various impurities might vary as such differences could cause large differences in the observed decontamination. Such differences are recognized to be a potential issue for several impurities such as $\mathrm{Cr}^{6+}$ and $\mathrm{V}$ and will continue to be evaluated. Impurities $(\mathrm{Cr}, \mathrm{Ni}, \mathrm{La}, \mathrm{Ta}, \mathrm{V})$ that have a smaller margin of confidence may deserve some continued attention as processing of the AFS-2 material progresses or through tracking/trending of the normal sample analysis protocol.

Process Scaling: Plant scale anion exchange equipment is typically 100 to 1000 times larger than laboratory equipment. Normally the process is scaled based on the linear velocity $\left(\mathrm{Q} / \mathrm{A}, \mathrm{mL} / \mathrm{min} / \mathrm{cm}^{2}\right.$ $=\mathrm{cm} / \mathrm{min}$ ) through the resin bed (which is related to residence time in the bed) and the loading profile of the resin. If a laboratory column contains resin at the same depth as the plant equipment, then scaling is primarily reduced to one of flow area and $\mathrm{Pu}$ flux through the bed (linear velocity will be the same). Higher $\mathrm{Pu}$ concentrations in the feed solution will produce a higher $\mathrm{Pu}$ resin loading. Lower flowrates would also tend to increase the effective loading by increasing the time for mass transfer. The HB-Line Pu anion columns nominally hold a 27 inch tall cylinder of resin, 7.62 inches ID (294.1 $\mathrm{cm}^{2}$ cross sectional area) which contains $\sim 20.1 \mathrm{~L}$ of $\operatorname{resin}^{15,16}$. For the non-radioactive experiments, a full-height settled resin volume of $194 \mathrm{~cm}^{3}$ was used in a $19 \mathrm{~mm}$ ID glass column, resulting in a cross sectional area of $2.835 \mathrm{~cm}^{2}$. The targeted flowrate of $10.7 \mathrm{~mL} / \mathrm{min} @ 4.5 \mathrm{~g} \mathrm{Pu} / \mathrm{L}$ for a $2.835 \mathrm{~cm}^{2}$ laboratory column was based on a cross-sectional area for the HB-Line column of $294.1 \mathrm{~cm}^{2}(7.62$ inches ID) and process loading rates of $1.1 \mathrm{~L} / \mathrm{min}$ at $4.5 \mathrm{~g} \mathrm{Pu} / \mathrm{L}^{15,17,18,19}$. This loading rate corresponds to $\sim 17 \mathrm{mg} \mathrm{Pu} / \mathrm{min} / \mathrm{cm}^{2}$. Table $2^{20}$ shows a comparison between the proposed HB-Line operating conditions, and current SRNL test conditions. A smaller diameter laboratory column (12.6 mm or 1.247 $\mathrm{cm}^{2}$ ) was used in the Pu experiments. This column consisted of two segments which contained a total of $68.6 \mathrm{~cm}^{3}$ of resin and was operated at flowrates that were roughly half those used in the larger nonradioactive column as shown in Table 2 .

\footnotetext{
${ }^{14}$ M. L Crowder, J. M. Duffey, "Task Technical and Quality Assurance Plan for Precipitation and Calcination of Plutonium(IV) Oxalate to Form Plutonium Oxide and Subsequent Gas Generation Studies to Support the MOX Feed Mission",SRNL-RP-2011-01657, Savannah River National Laboratory, Aiken SC, December 2011.

${ }^{15}$ E. A. Kyser, "Plutonium Loading onto Reillex HPQ Anion Exchange Resin", WSRC-TR-2000-00372, Westinghouse Savannah River Company, Aiken, SC (Sept 26, 2000).

${ }_{16}$ Drawing W720067 R44, "Savannah River Plant, Bldg 221H, 8 Inch Dia. Column Assembly Process, H363110-1,2,3 \& 4", (January 29, 1985).

${ }^{17}$ Drawing W720279 R0, "Savannah River Plant, Bldg 221H, Nept. 237, Plut. 239 Flow Diagram Process", (July 31,1981).

${ }^{18}$ Drawing W743159 R25, “Savannah River Plant, Bldg 221H, Enhancement of Pu 239 Capability, Flow Diagram Sh. No. 2 Process", (March 1, 1985).

${ }_{19}$ R. H. Smith, "HB-Line Pu-239 Production Flow Sheet Strategy", SRNS-E-1100-2011-00025, Rev. 1, (January 23,2012 ).

${ }^{20}$ E. A. Kyser,'Task Technical and Quality Assurance Plan for Plutonium Anion Exchange Flowsheet for HB-

Line”, SRNL-RP-2011-01598, Savannah River National Laboratory, Aiken SC, December 2011.
} 


\section{EXPERIMENTAL}

Ce and Pu Experiments: The initial experiments ( $\mathrm{Cr} 310$ and $\mathrm{Cr} 311)$ were performed in a single 27" tall column in a hood without any radioactive components. These initial experiments contained weakly absorbing Ce. Two experiments containing $\mathrm{Pu}$ were performed in a similar manner with the two-piece column installed in a glovebox. The two-piece column was necessary to achieve the required resin-bed height due to the limited height of the glovebox. Experiment $\mathrm{Cr} 313$ was performed to troubleshoot the equipment and experimental procedure and was very similar to experiment $\mathrm{Cr} 314$ except that the later experiment had a spike of ${ }^{137} \mathrm{Cs}$ added to the feed to simulate a non-interacting impurity that did not have significant analytical measurement limitations. Full sampling was never planned for $\mathrm{Cr} 313$, but additional samples were added based on the smooth operation of the experiment.

Resin Pretreatment: The Reillex HPQ ${ }^{\mathrm{TM}}$ resin that was tested came from the 1998 manufacturer's lot (\#80302MA) that was purchased by SRNL for Pu flowsheet work ${ }^{21}$ and later used for Np flowsheet work. All resin was initially converted from the chloride form (as-shipped) to the nitrate form by washing with $1 \mathrm{M} \mathrm{NaNO}_{3}(\sim 10 \mathrm{BV}$ in a column was the preferred method, but other methods are acceptable). The assembled column was thoroughly washed with $8 \mathrm{M} \mathrm{HNO}_{3}$ prior to the start of the experiment. Experiments $\mathrm{Cr} 310$ and $\mathrm{Cr} 311$ both used the same resin bed; experiments $\mathrm{Cr} 313$ and Cr314 used a different two-piece column apparatus.

Column Preparation: A sufficient quantity of resin was converted into the nitrate form prior to loading the column. The resin was loaded by slurrying the resin into the column with water to avoid air entrainment in the bed. The resin bed was settled by passing water/dilute $\mathrm{HNO}_{3}$ down-flow through the resin bed. No obvious gaps or void spaces were visible. The final resin bed volume was adjusted by adding a small amount of resin or removing excess resin with a slurry pipette to obtain the desired resin bed height. A 100 mesh 304L screen (see Figures 2a, 2b, and 3) was installed above the packed bed to retain the resin and allow for up-flow operation. This screen fit tightly within the column body and did not allow the resin bed to expand significantly. It also prevented upward flow from fluidizing the resin bed. Actual volume changes of the resin beads are insignificant (after the resin was in the nitrate form), but retained gas bubbles would cause the resin bed to expand without the screen installed. Gas bubbles trapped within the moist bed are often very difficult to remove and will cause channeling of the flow through the bed. A tightly held resin bed does not allow channeling to occur.

Lab Equipment: A picture of the column used in the non-radioactive experiments is shown in Figure 2. This column utilized \#7 Teflon ${ }^{\mathrm{TM}}$ bushings for connecting $1 / 4$ inch polypropylene tubing to the upper part of the column and consisted of a $19 \mathrm{~mm}$ ID glass body to retain the resin bed and a headpiece. The headpiece is attached to the column body with a Rodaviss ${ }^{\mathrm{TM}}$ joint to allow the column to retain a larger pressure head than that allowed by a ground glass joint. As a safety precaution, the headpiece also had an Ace glass pressure-relief valve. An additional arm with a stopcock and funnel allowed the column to be vented. The 3-way stopcock at the bottom of the column was used to change flow direction. With the 100 mesh screen held into place with an o-ring (Figure 2a), this column was operated with load-wash up-flow and elution down-flow. The Pu experiments used a twopiece column design (due to limited headroom in the glovebox) that used $1 / 4$ and $1 / 8$ inch polypropylene tubing to connect to the $12.6 \mathrm{~mm}$ ID glass body. The upper portion of the column used a similar headpiece to that used for the non-radioactive experiments. The bottom of the upper column was connected to the top of the lower column with $1 / 8$ inch tubing. The top and bottom of both the upper and lower columns used $12 \mathrm{~mm}$ diameter-100 mesh screen (similar to that shown in Figure $2 \mathrm{~b}$ ) to retain the resin. A 3-way Swaglok ${ }^{\mathrm{TM}}$ valve was used at the bottom of the lower column in much the

${ }^{21}$ W. J. Crooks, E. A. Kyser, S. R. Walters, "Qualification of Reillex ${ }^{\mathrm{TM}} \mathrm{HPQ}$ Anion Exchange Resin for Use in SRS Processes", WSRC-TR-99-00317, Westinghouse Savannah River Company, Aiken, SC (March 10, 2000). 
same way as the 3-way stopcock was used in the non-radioactive column. A sketch of the experimental setup for the up-flow load/wash steps is shown as Figure 4. A separate sketch of the downflow elution experimental setup is shown as Figure 5. Figures 4 and 5 show the installation of flowcells and fiber optics that were not in use for these experiments but will be used later in Pu loading experiments. The feed line was connected to the bottom of the column during condition, load and wash steps and then changed to the top of the column for elution (along with switching the 3-way stopcock/valve to the elution position). A standard FMI piston pump was used to pump feed, wash, or elution acid through the column.

Feed Matrix: Based on the previous review of the known impurities ${ }^{4}$, a feed matrix was prepared which contained all the significant non-radioactive impurities expected in AFS-2 metal feedstocks and the reagent impurities added during the dissolution process. Table 3 shows the target concentrations of impurities for testing in the current study.

Analytical Methods: Mass balance for impurities was determined by a combination of ICPES (Gd, B, Al, K, Fe, S, Si, Zn, Li, Na, Mg, Mn, Ce, Ca and Cu), IC Anions (F) and ICPMS (Ga, Ce, Gd, Sm and $\mathrm{W}$ ) analyses. It was understood that the detection limits for the current methods as performed by AD probably would have difficulty meeting some of the specification limits. Efforts were undertaken by $\mathrm{AD}$ in parallel ${ }^{22}$ with the current study to improve those detection limits where required (as possible). Over the course of this work several analytical adjustments were made. Samples for submission to ICPES were submitted in plastic vials due to apparent $\mathrm{Na}, \mathrm{B}, \mathrm{Si}$ and $\mathrm{Al}$ contamination that appeared to be associated with the glass sample vials commonly used. Due to interferences, $\mathrm{Pu}$ was removed from the primary anion product samples (commonly referred to as "Hearts") as well as the Displacement solutions. When Pu removal was not performed, both positive and negative interferences were observed by ICPES. Separate techniques were used to remove the Pu for ICPES and ICPMS. The ICPMS separation method, which is described in detail in another report ${ }^{22}$, involved isolation of the trivalent lanthanides by elution from an analytical column (Eichrom RE cartridge). All other heart components (except $\mathrm{Pu}$ ) were contained in the column raffinate. The ICPES separation method involved a separate analytical column type (Eichrom TEVA ${ }^{\circledR}$ Aliquat 336 cartridge) which removed the $\mathrm{Pu}$. The raffinate was subsequently analyzed for the remaining elements of interest without plutonium interference. Both methods involved the dilution of the Hearts sample prior to transfer to the columns by $10-13 \mathrm{x}$ with nitric acid and sodium nitrite solutions to promote complete conversion of the plutonium to the $4+$ valence state. Reagent blanks were tested and standard additions to reagent blanks and samples were performed to check for both contamination and recovery of the analytes of interest. The separation recoveries for the ICPES sample preparation were high, but in some cases variability in the standard spike additions may have been large relative to concentrations of the impurities resulting in inaccurate blank corrections. In addition, sodium analysis in these samples following plutonium removal was not possible due to the large additions of sodium reagents. It is also believed that some potassium may have been inadvertently added in the ICP-ES separation method (possibly as a minor impurity in the sodium reagents). These facts complicate the interpretation of the data for this element.

Reagents: Reagent grade chemicals were generally used with the exception of ferrous sulfamate (FS), for which H-Area plant production FS was used. The purity of the reagents for the preparation of the feed solution was not a significant concern. The purity of the wash and elution acid solutions was a concern due to their effect on the purity of the final product. Distilled water (from the SRNL laboratory system) and reagent grade $\mathrm{HNO}_{3}$ was used for preparation of all wash and elution acid solutions for $\mathrm{Cr} 310$ and $\mathrm{Cr} 311$. Deionized water was used for preparation of all wash and elution acid solutions for

\footnotetext{
${ }^{22}$ M.A. Jones, D.P. Diprete, B.J. Wiedenman, “Application of Column Extraction Method for Impurities Analysis on HB-Line Plutonium Oxide in Support of MOX Feed Product Specifications", SRNL-STI-2012-00148, Savannah River National Laboratory, March, 2012.
} 
$\mathrm{Cr} 313$ and $\mathrm{Cr} 314$. All sample and reagent bottles were pre-washed with deionized (DI) water (including a $24 \mathrm{~h}$ DI water soak step). All samples were collected in pre-weighed and pre-washed sample bottles to avoid cross contamination. After collection of these large samples, the filled bottles were weighed and the flowrate determined by the time required to fill each bottle and the density of each solution. In some instances, interruptions in the flow made the flowrate determination inaccurate. Since the flowrate was not easy to monitor as the experiment was performed, some flowrates (particularly the elution rates) were lower than intended, but the wash and elution volumes were well known. 


\section{RESULTS}

Feed Preparation: Feed solutions were prepared by dissolving reagents into water as shown in Table 4. Nitrate salts were used as the source of most impurities. Ludox HS-30 was used as a source of soluble silica. Tungstate proved to be difficult to maintain soluble in acid solution. Due to the cloudy appearance of the feed solution, Cr310 Feed was filtered with a $0.45 \mu \mathrm{m}$ filter at the start of the experiment and a small amount of yellow solids were removed. XRD analysis of the filtered solids indicated that they were tungstenic acid. Elevated levels of W were also measured in the Displacement sample during the elution cycle suggesting that some tungstenic acid was filtered out by the frit at the bottom of the column. Due to its limited solubility and the associated issues, W was not included in the test matrix for the later tests. Feed materials that actually contain $\mathrm{W}$ or other limited solubility elements will have to either be avoided or removed by filtration or other means to avoid operation issues in HB-Line and avoid contamination of the anion product. Analyzed results of each feed solution are shown in Tables 5a and 5b. The primary difference between the experiments $\mathrm{Cr} 310$ and $\mathrm{Cr} 311$ was that $\mathrm{Cr} 310$ contained both $\mathrm{B}$ and $\mathrm{Gd}$, whereas $\mathrm{Cr} 311$ only contained $\mathrm{B}$. It was intended that the feed solutions for all experiments have a 2 to 1 molar ratio of $\mathrm{Al}$ to $\mathrm{F}$, but $\mathrm{Cr} 311$ only had an $[\mathrm{Al}] /[\mathrm{F}]$ molar ratio of 0.2 . The low $[\mathrm{Al}] /[\mathrm{F}]$ ratio is presumed to have an effect on speciation and if $\mathrm{Pu}$ had been present would have resulted in increased losses. Elements $(\mathrm{Pu}, \mathrm{Al}, \mathrm{Ce}, \mathrm{Fe}, \mathrm{Ga}, \mathrm{Gd}, \mathrm{Sm}$, and $\mathrm{Si}$ ) that form complexes with $\mathrm{F}$ would be likely candidates to be affected by the low $[\mathrm{Al}] /[\mathrm{F}]$ ratio in the feed. However it is not apparent that the behavior of any impurity was significantly different between experiments $\mathrm{Cr} 310$ and $\mathrm{Cr} 311$.

Table $5 \mathrm{~b}$ shows the analyzed feed data for the $\mathrm{Pu}$ experiments were comparable to that shown in Table $5 \mathrm{a}$ for the non-radioactive $\mathrm{Ce}$ experiments. The Pu experiments generally used similar concentrations of impurities as those used in the Ce experiments with several differences. 1) Based on $\mathrm{H}-$ Canyon's request, the concentration of B was increased from $\sim 1 \mathrm{~g} \mathrm{~B} / \mathrm{L}$ to $\sim 1.7 \mathrm{~g} \mathrm{~B} / \mathrm{L}$. 2) $\mathrm{W}$ and Ce were dropped from the feed matrix. 3) $\mathrm{Pu}$ and Am were added to the feed matrix. 4) ${ }^{137} \mathrm{Cs}$ was added to the feed matrix for $\mathrm{Cr} 314$ as a non-interacting cationic species with a very low detection limit.

Flow Rates: Targeted and measured solution flowrates for column tests $\mathrm{Cr} 310, \mathrm{Cr} 311, \mathrm{Cr} 313$ and $\mathrm{Cr} 314$ are provided in Table 6 . The flow rates were determined from the mass of solution collected in each bottle, the measured solution densities, and the recorded collection times. The average flow rate in each test for the column loading period with AFS-2 feed simulant was typically within $20 \%$ of the target value (a few cases it was up to $40 \%$ off). Due to a calculation error, the average flow rates used for the elution phase for the Ce experiments were only $26 \%(\mathrm{Cr} 310)$ and $38 \%(\mathrm{Cr} 311)$ of the targeted value. As a result of the especially low elution flow rate used in $\mathrm{Cr} 310$, the Hearts and Tails bottles for this test contained only $0.5 \mathrm{BV}$ of solution each. The low elution flow rates could result in a shifting of the Hearts peak into the Tails sample due to the Displacement and Hearts samples being too narrow but there is no indication in the results that this occurred to any significant extent with any of the impurities. Some impurities (Gd, Sm, W) did appear to peak prior to the Hearts cut but the cause of this behavior is not understood.

Hearts Impurity Concentrations: The calculated values for the impurities on a Pu basis are shown in Table 7. Since extensive washing was performed on the Ce experiments, most of the impurity concentrations are at or near the detection limits. The concentrations of $\mathrm{S}$ were near the detection limit with the calculated impurity concentrations near the Column A specification. Boron, Si and Sm were initially near the specification limits but upon reanalysis in plastic sample vials both B and Si were reported at less than the method detection limit (MDL). Samarium challenges the specification due to the slight adsorption by the anion resin and the low specification limit. Gadolinium was below the Column A specification in the Ce experiments but a small adsorption peak does exist. The results for the Hearts samples for the Pu experiments ( $\sim 10 \mathrm{BV}$ wash) are less favorable. Boron, $\mathrm{Gd}, \mathrm{K}$, and Sm 
were reported at above the Column A specification limit and the sulfur MDL was above the specification limit. All Hearts sample from $\mathrm{Cr} 313$ and $\mathrm{Cr} 314$ results except $\mathrm{Na}$ are reported by analysis after $\mathrm{Pu}$ removal. Impurity removal in the $\mathrm{Pu}$ experiments was significantly lower than observed in the $\mathrm{Ce}$ experiments possibly due to a physical trapping of impure feed solution by the $\mathrm{Pu}$ hexanitro species. Further detailed results are shown in the following pages for each impurity or groups of similar impurities with discussion of observations.

Material Balance: All solution that passed through the column was collected over a period of time and analyzed as a series of composite samples. No grab sampling was performed. A material balance was calculated for each experiment for each impurity using the measured volumes and densities of each sample from the wash and elution steps (Tables 8a, 8b and 8c). Most impurities were present in similar concentrations for all experiments but $\mathrm{Al}$, and $\mathrm{Gd}$ are different in $\mathrm{Cr} 311$, W was only included in $\mathrm{Cr} 310$ and ${ }^{137} \mathrm{Cs}$ was only included in $\mathrm{Cr} 314$. The bulk of most impurities (except for Ce) passed through the column into the effluent/raffinate samples. The material balances for these elements generally were closed within a few percent. Several impurities (Ce, Li, Si, W) had some significant issue(s) which prevented better closure of the material balance. Notably, Li, and Si suffered from analytical difficulties. Tungsten (and probably $\mathrm{Si}$ ) appeared to have solubility limitations in acid solutions. Cerium did not have a particularly good material balance at 80 to $96 \%$ of the feed.

Wash and Elution Acid Purity: Analysis of these reagents after the initial Ce (nonradioactive) testing identified B and Si contamination that was suspected to be due to either the distilled water source or the glass sample vials used for submission to AD. Samples of the distilled water and nitric acid sources submitted to $\mathrm{AD}$ in plastic vials eliminated these as sources of the impurities. A fresh sample of Cr310 WC7-10 (collected and stored in a washed plastic bottle) was analyzed and compared to the previous analysis. The reanalyzed values for both B and Si were significantly lower ( and less than the detection limits). The reanalyzed value for $\mathrm{Al}$ was significantly lower, but still slightly above the detection limit. Based on these results, the samples beyond $\mathrm{Cr} 310$ and $\mathrm{Cr} 311 \mathrm{WC} 3$ were resubmitted for analysis by ICPES in plastic vials. The results for ICPES shown in this report (where the impurity concentrations are low) are reported for samples stored in plastic vials to avoid further issues. Future work will avoid this issue by using plastic sample vials for ICPES samples.

Plutonium: Plutonium was included in the feed matrix for $\mathrm{Cr} 313$ and $\mathrm{Cr} 314$ based on the nominal flowsheet $^{3}$. Figure 6 shows that $\mathrm{Pu}$ is strongly loaded onto the resin and with minor losses of $\sim 1.5 \%$ by $10 \mathrm{BV}$ 's of an $8 \mathrm{M} \mathrm{HNO}_{3}$ wash. There is a sharp elution peak that averaged $\sim 10$ times the feed solution concentration.

Americium: ${ }^{241}$ Americium is a daughter product of ${ }^{241} \mathrm{Pu}$ in the weapons grade $\mathrm{Pu}$ and thus is always present in a measureable amount in the feed to $\mathrm{Pu}$ anion exchange. Am is generally reported as being separated by anion exchange from Pu but as can be seen in Figure 6 and Tables $8 \mathrm{~b}$ and 8c, there appears to be some slight retention by the resin. Americium is steadily washed from the resin and a 10 BV wash appears capable of removing $>99.4 \%$ (DF $>160$ ) of the Am (see Table 8b and 8c). After purification, ${ }^{241} \mathrm{Am}$ continues to grow into the Hearts solution at a rate that depends on the ${ }^{241} \mathrm{Pu}$ content of the solution. Analytical results for ${ }^{241} \mathrm{Am}$ were corrected to the time of separation.

Cerium: Cerium was included in the feed matrix for the non-radioactive experiments based on past experience that it does not easily wash from the resin column. It serves as a weakly absorbing surrogate for $\mathrm{Pu}$. Figure 6 shows that $\mathrm{Ce}$ is moderately loaded onto the resin and slowly washed away by an $8 \mathrm{M} \mathrm{HNO}_{3}$ wash. It is retained significantly more strongly than Am. Distinct elution peaks were observed that were comparable in concentration to the feed solution. Cerium was measured by both ICPES and ICPMS and good agreement between the methods was generally seen except for the Dis- 
placement and Tails samples. Table 9 shows a Ce DF of $\sim 10$ based on the amount of wash volumes used in these experiments.

Gadolinium: Gadolinium is one of the proposed neutron poisons for use in the dissolution flowsheet in H-Canyon. Like many of the other rare earth elements, $\mathrm{Gd}$ is weakly absorbed on the resin column and took significant wash volumes to remove (Figure 7). The bulk of the Gd is removed in the initial four BV's of wash, but after that point in the wash cycle it appears that the Gd removal is slow. The slow removal seems likely to be due to the affinity of Gd for the resin. Due to the low limits for Gd in Table 1, a larger amount of washing is required to meet the proposed ICD limits. A DF on the order of 15,000 was achieved in Cr310 with 19 BV of wash but a DF of only 3000 was observed during the $\mathrm{Pu}$ experiments after $10 \mathrm{BV}$ 's wash. There was significant discussion about which of the 5 abundant mass numbers of naturally occurring Gd to use for DF calculations. Initially it was realized that mass number 156 had a $\mathrm{Ce}-140(\mathrm{Ce}+\mathrm{O}, 140+16=156)$ interference which made it inappropriate. The ICPMS instrument manufacturer's recommendation was to use Gd-158 which was initially used. Further inspection of the data revealed that the Gd-157 and Gd-158 results were significantly higher than the Gd-155 and Gd-160 lines. It is possible that Ce-142 could cause a similar, but smaller interference with mass number $158(\mathrm{Ce}+\mathrm{O}, 142+16=158)$. It was also suggested that an $\mathrm{OH}$ interference is possible with $\mathrm{Ce}-140(\mathrm{Ce}+\mathrm{OH}, 140+17=157)$ that could account for interference at mass number 157. We have concluded that Gd-155 and Gd-160 are the best representation of the behavior of Gd when $\mathrm{Ce}$ is present in the feed solution. When $\mathrm{Ce}$ is not present, all the common mass lines of $\mathrm{Gd}$ appear to be reasonably equivalent.

Gadolinium was included in the feed matrix for $\mathrm{Cr} 310, \mathrm{Cr} 313$ and $\mathrm{Cr} 314$ experiments and was analyzed by both ICPES and ICPMS. Data from both methods are shown (in Figure 7) for Cr310 but the ICPES analyses had a limited detection limit and the data beyond 5 BV's of wash were not meaningful. Experiment Cr311 analyses showed a very small amount of $\mathrm{Gd}$ in the feed, possibly as an impurity in the Sm, but those data are at too low of a concentration to be meaningful. Cr 314 had significantly more Gd present in the Wash and Hearts samples than was previously observed. This result has been tentatively explained as being related to a physical trapping of impurity within the resin structure by the $\mathrm{Pu}$ hexanitrato species which is absorbed onto the anion resin loading sites.

Based on our current interpretation of interferences, it does appear that 19 BV's of decontamination wash in experiment $\mathrm{Cr} 310$ easily achieved the $3 \mu \mathrm{g} \mathrm{Gd} / \mathrm{g}$ Pu specification but when a representative quantity of $\mathrm{Pu}$ was present, $10 \mathrm{BV}$ 's of decontamination wash in experiments $\mathrm{Cr} 313$ and $\mathrm{Cr} 314$ resulted in product that was 7-8 times $(\sim 24 \mu \mathrm{g} / \mathrm{g} \mathrm{Pu})$ the $3 \mu \mathrm{g} \mathrm{Gd} / \mathrm{g}$ Pu specification.

Samarium and Gadolinium: Samarium at a modest impurity concentration was included in these experiments as a comparison for the Gd behavior. Figure 8 shows a comparison between $\mathrm{Sm}$ and $\mathrm{Gd}$ as contrasted with Ce. Gadolinium and Sm behaved very similarly even though less Sm was added. The Sm peaks show a difference in shape for the Ce experiments due to an increase in the Sm concentration in the Displacement sample prior to the Hearts sample. Because the elution rates and volumes were low, this result may not have much significance. It appears that the distribution coefficient $\left(\mathrm{K}_{\mathrm{d}}\right)$ for Sm is slightly larger than for Gd. Samarium is not expected to be present in any concentration in the feedstocks nor the process. All major mass numbers for Sm appear to give equivalent results. Due to apparent higher $\mathrm{K}_{\mathrm{d}}$ for $\mathrm{Sm}$, it appears that 15-20 BV's of decontamination wash are required to remove Sm to the Column A specification limits without Pu present but greater than 30 BV's when $\mathrm{Pu}$ was present in the feed.

Boric Acid (B): Boric acid is the alternative H-Canyon neutron poison for Gd and was included in all experiments. In the initial analyses there were B contamination problems attributable to the glass vials in which the analytical samples were stored prior to analysis. When reanalyzed following storage 
in plastic vials (the experimental solutions were all stored in clean plastic bottles rather than glass), samples after 5 BV's of wash in the Ce experiments had B at less than the ICPES MDL of $\sim 0.2 \mathrm{mg}$ $\mathrm{B} / \mathrm{L}$ (Figure 9). In the Pu experiment, the rate of B removal by washing slowed after 3 BV's and an elution peak was present. Boron DF's of $\sim 60,000$ (17-19 BV's wash) were observed for the Ce experiments but this value fell to 2000 (10 BV's wash) when Pu was present. The B in the Hearts cut increased from $<4.5$ to $\sim 150 \mu \mathrm{g} \mathrm{B} / \mathrm{g} \mathrm{Pu}$ (see Table 7) when $\mathrm{Pu}$ was added to the experiments and the wash volume was reduced from $\sim 19$ to10 BV. With a Column A specification of 100, the results from $\mathrm{Cr} 313 / 4$ marginally exceed the specification, but estimates shown in Table 10 place the required BV's wash as high as 20 to meet the specification. The bulk removal of B initially occurs during the first 3-4 BV of wash volume (Figure 9), but when $\mathrm{Pu}$ is present the slope of the curves indicate that less B is being washed from the column. After 5 BV's of wash, significantly more B was still being removed during the experiment with Pu compared with that observed during the Ce experiments.

Boric Acid (B), Gd and Ce: Figure 10 shows a comparison of the B and Gd removal as compared to Ce. Gd analyses by ICPMS are more sensitive than ICPES for either Gd or B. Gd appears to have a small elution peak in all experiments. B did not appear to have an elution peak in the Ce experiments but an apparent peak is present in the $\mathrm{Pu}$ experiment $\mathrm{Cr} 314$. The difference between the Column $\mathrm{A}$ specifications for $\mathrm{Gd}$ and $\mathrm{B}(100 \mu \mathrm{g} \mathrm{B} / \mathrm{g}$ Pu vs. $3 \mu \mathrm{g} \mathrm{Gd} / \mathrm{g} \mathrm{Pu})$ makes it more practical to achieve the purity specification with $\mathrm{B}$ as the neutron poison in the H-Canyon dissolution process. Use of $\mathrm{Gd}$ could be reconsidered if its specification could be raised to a similar level. Boron does pose analytical risks as sample and reagent contamination is more likely with B than Gd due to its abundance in nature.

Alkali Metal (1A) Impurities - 1+ Valence (Li, Na, K, Cs): Figure 11 shows the behavior of the alkali metals that were included in the feed solution compared to $\mathrm{Pu}, \mathrm{Am}$ and $\mathrm{Ce}$. The alkali metal elements are not expected to have any interaction with the resin and high DF's are thus expected. Analytical problems limit the results for most of these elements and for this reason ${ }^{137} \mathrm{Cs}$ was included in the feed for the $\mathrm{Pu}$ experiment. Lithium, $\mathrm{K}$ and $\mathrm{Na}$ appeared to reach the detection limit for ICPES after 2-3 BV of wash. The rate of Cs removal slowed significantly beyond $\sim 5$ BV's wash and an apparent elution peak was observed. We presume that the apparent Cs elution peak represents Cs that was physically trapped in the resin structure by the large Pu hexanitrato complex. The ICPES analyses for $\mathrm{K}$ of the Displacement and Hearts showed a similar (but larger) elution peak, but that analysis had a large background in the reagent blank that complicates interpretation of those data. The final Hearts analysis showed that $\mathrm{K}$ was above the Column A specification level but that value had a high uncertainty due to the reagent blanks. Table 10 shows predictions that $\mathrm{Li}, \mathrm{Na}$ and $\mathrm{K}$ would all make Column A specification after 4 BV's of wash (using the Method B calculation for K discussed later in Discussion and Application section). The Table 10 prediction for $\mathrm{K}$ is inconsistent with the $\mathrm{K}$ impurity result in the Table 7. The 1+ valence elements are likely removed to the Column A specification limits within the first few BV's of decontamination wash but the K result on the Pu experiment provides a single contradictory result.

Impurities with 2+ Valence (Ca, Mg, Cu, Mn, Zn): Figure 12 shows the behavior of the 2+ valence impurities that were included in the feed solution compared with $\mathrm{Pu}, \mathrm{Am}$, and Ce. These impurities are reported to have no interaction with nitrate anion exchange resin and appeared to reach background concentrations after 2 to 5 BV's of wash. These elements were all measured by ICPES. The ability to measure a high DF is limited by the ability of the analytical detection method to consistently measure low concentrations. Manganese has a particularly low detection limit and allows for confirmation of a high DF and observation of an elution peak similar to that observed for Cs. Other elements such as $\mathrm{Cu}, \mathrm{Ca}, \mathrm{Zn}$ and $\mathrm{Mg}$ have higher detection limits. The Ca values for $\mathrm{Cr} 311$ were near the analytical reporting limit. The DF's for $\mathrm{Ca}, \mathrm{Cu}, \mathrm{Mg}$ and $\mathrm{Zn}$ were limited by the small amount of each element in the feed and the detection limits for these elements by ICPES. The Pu test may show 
a small elution peak for $\mathrm{Mn}$, but detection limitations did not allow the identification of an elution peak for $\mathrm{Ca}, \mathrm{Mg}, \mathrm{Cu}$ or $\mathrm{Zn}$. The 2+ valence elements appear to be removed to the Column A specification limits within the first 2 to 4 BV's of decontamination wash.

Gallium: Figure 13 shows the behavior of the Ga included in the feed solution compared with $\mathrm{Pu}$, Am and Ce. Ga was measured by ICPMS and mass number 69 was used for this plot. Mass number 71 may have interference from doubly-charged ${ }^{142} \mathrm{Ce}$ for the Ce experiments and shows significantly different results. The Ga results are shown separately as the analytical method is currently being extended to improve the $\mathrm{Ga}$ detection limit and the interferences may not be fully understood. These results are near the detection limit for Ga by the instrument and method used in the analysis. The results from the Ce experiment suggest that there may be a small Ga elution peak but this is somewhat ambiguous in the $\mathrm{Pu}$ experiment even though it does appear that higher levels of $\mathrm{Ga}$ were present in the three eluate samples. Gallium will not be considered a specification problem as the Column A allowable concentration is high but its accurate quantification at low concentrations poses some limitations if we attempt to produce material at the Column B limit.

Impurities with 3+ Valence (Al, Fe, Ga): Figure 14 shows the behavior of the $\mathrm{Al}, \mathrm{Fe}$ and $\mathrm{Ga}$ that were included in the feed solution compared with $\mathrm{Pu}, \mathrm{Am}$ and $\mathrm{Ce}$. Aluminum and $\mathrm{Fe}$ are significant process-added impurities and Ga is the major feedstock impurity in AFS-2 metals. Generally these elements behave similarly (as expected), with the bulk of the impurities in the feed solution removed from the column in the initial 3 to 5 BV's of wash. Beyond 3 to 5 BV's, these results suggest that the concentrations are either below the detection limit or near enough to introduce variability in the results. The $\mathrm{Cr} 311 \mathrm{Al}$ results appear different due to the lower concentration of $\mathrm{Al}$ that was used in the feed, but the Al concentration beyond 5 BV's was similar for both experiments. The Al results in all experiements were often limited by the detection limits but higher concentrations were observed in the elution samples, particularly in Cr314. These three 3+ valence elements (Al, Fe, Ga) appear to be easily washed to less than $10 \%$ of the Column A specification with the 10 to 19 BV's of wash that was used in these experiments. The $3+$ valence elements appear to be removed to the Column A specification limits within the first 2 to 3 BV's of decontamination wash. Elevated concentrations of $\mathrm{Al}$ and $\mathrm{Fe}$ were measured in the Hearts samples for the $\mathrm{Pu}$ experiment but the concentrations were still $<50 \%$ the Column A specification after 10BV's of wash.

Anion Impurities (Sulfate, F, Formate): Figure 15 shows the behavior of the sulfate, $\mathrm{F}$ and formate which were included in the feed solution. Formate is present due to its use as a stabilizer in the Ludox HS-30 that was used as the Si source. The amount of formate measured in the feed for the Ce experiments was higher than expected from the information provided on the Material Safety Data Sheet but the manufacturer did not make clear how much the formate concentration might vary. Similar levels of formate were not found in the Pu experiment even though a larger amount of Ludox HS30 was used in both the Cr313 and Cr314 Feed preparation. The IC anions analytical method is not as sensitive as the other analytical techniques that we are using but the data obtained do show that these anions are washed out to the detection limits within 2 to 3 BV's of wash during the Ce experiments. Due to the measurement limitations for the concentration of $\mathrm{F}$ and $\mathrm{Cl}$ in the $\mathrm{Feed} /$ Raffinate solutions, no DF measurement was attempted in the $\mathrm{Pu}$ experiments. Neither formate nor sulfate is expected in the HB-Line feed solution. The detection limit for $\mathrm{F}$ in the Hearts samples was significantly higher than the Column A specification limit ranging from $<2000$ to $<10,000 \mu \mathrm{g} / \mathrm{g} \mathrm{Pu}$. Additional work is planned to investigate the behavior of $\mathrm{F}$ in oxalate precipitation and calcination to measure the additional DF provided by those process steps since F will be added in the H-Canyon dissolution process. Analytical detection limits prevent meaningful determination of the removal of $F$ to meet the Column A specification. The analytical detection limits for S by ICPES are expected to be comparable to the Column A specification, but due to the lack of sulfate in the production process, $\mathrm{S}$ is not expected to pose a signification process risk. 
Polymeric Impurities (W, Si): Figure 16 shows the behavior of the W and Si that were included in the feed solution compared with $\mathrm{Pu}, \mathrm{Am}$ and $\mathrm{Ce}$. The feed solution from $\mathrm{Cr} 310$ was cloudy and solids were removed by filtration just prior to the experiment. Analysis of those solids found tungstenic acid as the only component. An apparent peak in the Displacement sample can be observed in the W results in Figure 16 which may be due to polymeric solids that were washing from the frit at the bottom of the column at the start of the elution step. Silica, possibly existing in colloidal form, has a somewhat erratic behavior in these experiments. For the Ce experiments, Si was initially observed in the $2-6 \mu \mathrm{g} / \mathrm{mL}$ concentration in most of the check standards. Reanalysis of the reagent blanks in plastic vials indicated that the original glass sample vials were the source of the Si contamination. The glass ion exchange column did not appear to contribute significant amounts of Si probably due to the relatively short contact time. Re-measurement of the wash and elution samples from the Ce experiments ( $\mathrm{Cr} 310$ and $\mathrm{Cr} 311)$ lowered the Si concentration in many samples to the AD detection limit. The values for Si measured in the elution samples were limited by the amount of Si observed in the reagent blank for the Pu separation method used on those samples. The concentrations of Si measured in the product samples all appear to be less than $50 \%$ of the Column A specification, but Si is a species that is challenging to control by anion exchange and it would not be desirable to allow significant Si to be introduced into the process. The concentrations of Si that were studied and analytical limitations prevented the measurement of DF's for Si to $<150$.

\section{DISCUSSION AND APPLICATION}

Required Wash Volume Estimates: Estimates of the wash volumes required to achieve the Column A purity limits for the heart cut are provided in Table 10 for each element added to the AFS- 2 feed simulant (excluding $\mathrm{Ce}$ and $\mathrm{Cu}$, for which no specified limits exist). These estimates were calculated using the measured amounts of each element in the various wash samples for each test (Method A). To determine the minimum wash volume, the mass of the element present in each successive wash bottle starting from the last was added to the amount in the product bottle until the calculated impurity level (in $\mu \mathrm{g} / \mathrm{g} \mathrm{Pu}$ ) exceeded the specified limit. The product volume was assumed to be $150 \mathrm{~mL}$ or $0.77 \mathrm{BV}$ and the heart Pu concentration was assumed to be $50 \mathrm{~g} / \mathrm{L}$ in these calculations for the Ce experiments while actual values were used for the $\mathrm{Pu}$ experiment. For samples containing less than the detectable limit of an element, it was assumed that the sample actually contained the detectable limit for that element (Table 10, Note a). For samples where the analyses are not particularly sensitive to the impurity (e.g. K and S), Method A for estimating the minimum required wash volume is not particularly useful as that method will predict a relatively high wash volume requirement even though most of the impurity appeared to be quickly washed from the resin.

For those cases where the element is presumed to have no chemical interaction with the resin, an alternate calculation method was used to estimate the minimum wash volume. In this alternate calculation method (hereafter referred to it as Method B), the assumption is made that the amount of impurity in a Hearts "peak" is not significant and the level of impurity in the later BV's of wash solution is not significant. The point in the wash curve where the impurity concentration (in $\mathrm{mg} / \mathrm{L}$ ) drops to the value required to reach the specification limit at the Hearts Pu concentration is then used as a minimum estimate for the required wash volume. In Table 10, Method B was used for $\mathrm{K}$ and $\mathrm{S}$ for all three experiments and then for Si in $\mathrm{Cr} 311$.

Although a small elution peak was observed in the Gd and the Sm concentration profiles, the larger wash volume needed to achieve the specification is primarily due to the fact that the Column A limits for these elements are low ( $3 \mu \mathrm{g} / \mathrm{g}$ Pu for $\mathrm{Gd})$ compared with most other elements. When $\mathrm{Pu}$ was present, the minimum wash volumes increased by at least a factor of two. 
Precipitation DF: An additional decontamination factor can be estimated for the subsequent plutonium oxalate precipitation process for impurities expected to remain soluble during precipitation such as $\mathrm{B}$ as boric acid. The DF from precipitation can be calculated considering the dilution of the $\mathrm{Pu}$ product by the addition of oxalic acid and that only a fraction of the total impure solution volume remains in the plutonium oxalate cake after filtration. The flowsheet strategy document indicates that the addition of oxalic acid to the precipitator feed solution will result in dilution of the concentration by a factor of 1.9. ${ }^{19}$ Precipitation tests conducted at SRNL have shown that a typical plutonium oxalate filter cake contains approximately $27 \mathrm{wt} \%$ residual liquid. ${ }^{23}$ Based on this information, a theorical DF of 46 is expected during precipitation and filtration of the Pu product from anion exchange, neglecting any chemical affinity or trapping for the species. This estimated DF, coupled with the purification achieved by the $10 \mathrm{BV}$ 's wash, drives the expected concentration of the impurity elements in the product oxide to well below the column A specifications. It has to be emphasized that the assumption that any impurity will remain soluble has not been experimentally validated and it is possible that unanticipated co-precipitates including these elements could form during plutonium oxalate precipitation that would reduce the expected DF. The estimated DF clearly would not apply to such impurities as Gd, Sm, Am, Ce, and Th but would likely apply to boric acid and $\mathrm{K}$ which were problematic in the current study. Experimental verification of the decontamination of these species across precipitation and calcination is recommended.

Comparison of B with Cs: Boron, Al, K, F and Fe are all present in the feed at relatively high concentrations both on a mass basis as well as a molar basis. Of these major impurities, B has the lowest specification limit. Although most of this work was done on a mass basis, it is more appropriate to treat the removal efficiency on a molar basis as individual molecules must be washed from the resin bed and the higher molecular weight species are weighed higher. Figure 17 shows washing behavior of the major elements that can be measured for the Pu experiment. This graph shows $\mathrm{Cs}, \mathrm{Al}$ and $\mathrm{Mn}$ all having similar wash behavior. The slope of the wash region appeared to be different for $\mathrm{Gd}, \mathrm{Fe}$ and $\mathrm{B}$ than for $\mathrm{Cs}, \mathrm{Al}, \mathrm{Mn}$ with $\mathrm{Gd}, \mathrm{Al}$ and $\mathrm{B}$ a somewhat like Am. Potassium is not shown since many of the values of the wash were below the MDL even though the Hearts sample appeared to contain some $\mathrm{K}$. The $\mathrm{K}$ analyses for the $\mathrm{Pu}$ product samples have additional uncertainty caused by the high reagent blanks for several impurities including K. Although the $\mathrm{K}$ result cannot be dismissed, it may not be accurate. Even though $\mathrm{K}$ did not make the Column A specification in the Pu experiment, it is expected to behave similarly to $\mathrm{Na}, \mathrm{Li}$ and $\mathrm{Cs}$ and it seems likely that during production it would be a problem only to the extent that the feed impurity levels are very high. Any additional DF such as in precipitation (as described above) will allow $\mathrm{K}$ to make the Column A specification.

We have theorized that it is likely that some impure feed solution could be physically "trapped" or "blocked" inside the porous resin structure and then later released as the Pu is released during elution. Since Pu gradually exchanges loading sites during the wash step as Pu migrates down the length of the column, some impure solution will be released as the wash continues. Also since the molecular species are of different sizes and have different diffusivities, some species will "escape" or "bleed" from the resin structure at a higher rate than others. There is much in the results from these experiments that is consistent with that theory and similar observations have been seen by others ${ }^{24,25}$. Although there is still much that we cannot explain, we conclude that there are at least two credible explanations for lower wash concentration ratios: 1) if the impurity species has already been washed from the column, it's bleed rate would be lower, and 2) if the diffusivity of a impurity species is rela-

\footnotetext{
${ }^{23}$ M. L. Crowder, "Pu Oxalate Cake Density", SRNL-NB-2012-00010, Savannah River National Laboratory, Aiken, SC, (April, 2012).

${ }^{24}$ E. Bluhm, F. Coriz, K. Abney, S. Balkey, et al., "Plutonium Oxide Polishing for MOX Fuel Fabrication", LA-UR-03-7565, Los Alamos National Laboratory, Los Alamos, NM, October 2003.

${ }^{25}$ D. B. James, W. A. Beyer, "Processing of Plutonium by Ion Exchange VIII. Self-Diffusion Studies in AnionExchange Resin", LA-3534, Los Alamos National Laboratory, Los Alamos, NM, June 1966.
} 
tively low, then it bleed rate would also be lower. Of course if the impurity species is weakly absorbed onto the resin, then it will continually bleed into the wash. This is the behavior that we seem to see for $\mathrm{Ce}, \mathrm{Sm}$ and $\mathrm{Gd}$ in all of the experiments. The B results on the Pu experiment seem different in that we did not see significant bleeding of B after about 5 BV's wash in the Ce experiments but in the $\mathrm{Pu}$ experiment $\mathrm{B}$ was very similar to $\mathrm{Gd}$. We do not believe that $\mathrm{B}$ had any interaction with the resin, but the results from the Pu experiment make us consider that as a possibility. Since we did not see this behavior during the Ce experiments, it seems likely that there is another mechanism at work here that we do not recognize.

Only the two anionic impurities $\mathrm{F}$ and $\mathrm{S}$ could not be confirmed to be removed to below the Column A specification by the washing step in these experiments and this was believed due to analytical limitations.

Based on the estimates shown in Table 10 and after consideration of the effect of measurement limitations it is believed that the Column A specification can be achieved with 10 BV's of wash for most elements expected in the feed. Gadolinium and Sm could require significantly more wash volume if those elements were present in the process due to the relatively low specification limits. However, neither is expected in the feedstock or process in other than trace concentrations. The large concentration of B used in the feed solutions and the moderately low limit make B specification difficult to achieve by anion exchange alone.

A minimum wash volume table for Column B specification is included as Table 11. Since many of the impurities (other than the neutron absorbing elements) have similar limits, many of the values are similar to those in Table 10. Boron, $\mathrm{Ga}, \mathrm{Gd}$ and $\mathrm{Sm}$ would require a significant additional wash volume over the 10 BV's recommended for the Column A specification. Elimination of those impurities from the feedstock and the dissolution flowsheet would appear to be the best strategy for a flowsheet to prepare material to achieve that specification.

Disclaimer: This report involves the analysis of many individual data points, many of which are near the detection limit of the analytical techniques or involve interferences between elements. The results contained in this report are the best available at the time this report was written. Detection limits are somewhat subjective and in some cases could be interpreted differently.

\section{RECOMMENDATIONS}

There are several impurity issues that are not completely resolved. The following are recommendations to address the limitations of the work performed thus far.

- The analytical limitation for analysis of $\mathrm{F}$ and $\mathrm{Cl}$ in $\mathrm{Pu}$ solutions should be addressed by performing a precipitation/calcination test with $\mathrm{Pu}$ product solution from this work and both with and without $\mathrm{F}$ and $\mathrm{Cl}$ added to determine a combined $\mathrm{DF}$ for those anions across precipitation and calcination. Analysis of the product oxide from this test by pyrohydrolysis is expected to establish sufficient basis for the necessary DF for these species.

- Verification of the estimated DF for B in precipitation is important as the opportunity for coprecipitation of impurities is possible. A similar technique as has been proposed for $\mathrm{F} / \mathrm{Cl}$ with re-dissolution of the oxalate or oxide and analysis by ICPES or ICPMS (F/H Area Laboratories) is a likely route to verify that a significant DF for B should occur.

- Although S (as sulfate) is not expected in either the feed materials or in the process reagents, measurement of oxide samples by $\mathrm{C} / \mathrm{S}$ analysis is expected to show a significant $\mathrm{DF}$ for $\mathrm{S}$ and may be worthwhile. 
- Even though the Pu testing had difficulty obtaining a $\mathrm{K}$ analytical result that was within the specification for the $\mathrm{Pu}$ product from anion exchange, this was somewhat dismissed as an analytical problem. This uncertainty should be reduced by further improvement in the separation method used to remove Pu as an ICPES sample preparation step and will be needed for the integrated demonstration. Alternate paths would include analysis for K by AA or ICPMS (by $\mathrm{F} / \mathrm{H}$ laboratories).

\section{CONCLUSIONS}

Use of Gd as a neutron poison would appear to require a larger volume of wash for the proposed Column A specification. However since B has a higher proposed specification and is more easily removed by washing, it appears to be the better candidate for use in the H-Canyon dissolution process. Some difficulty was observed in achieving the Column A specification due to the limited effectiveness that the wash step has in removing the residual B after $\sim 4$ BV's wash. However a combination of the experimental 10 BV's wash results and a calculated DF from the oxalate precipitation process yields an overall DF sufficient to meet the Column A specification. For those impurities (other than B) not removed by $10 \mathrm{BV}$ 's of wash, the impurity is either not expected to be present in the feedstock or process, or recommendations have been provided for improvement in the analytical detection method or validation of calculated results. In summary, boron is recommended as the appropriate neutron poison for H-Canyon dissolution and impurities are expected to meet the Column A specification limits for oxide production in HB-Line. 


\section{APPENDIX: Figures and Tables}


Table 1. Draft $\mathrm{PuO}_{2}$ Specification Limits.

\begin{tabular}{|c|c|c|c|c|}
\hline \multicolumn{2}{|c|}{ Chemical Component } & \multirow{2}{*}{$\begin{array}{c}\text { B } \\
\mu \mathrm{g} / \mathrm{g} \mathrm{Pu} \\
100\end{array}$} & \multirow{2}{*}{$\begin{array}{c}\begin{array}{c}\mathrm{A} \\
\mu \mathrm{g} / \mathrm{g} \mathrm{Pu}\end{array} \\
250\end{array}$} & \multirow{2}{*}{$\begin{array}{c}\text { Exceptional } \\
\mu \mathrm{g} / \mathrm{g} \mathrm{Pu}\end{array}$} \\
\hline $\mathrm{Ag}$ & (Silver) & & & \\
\hline $\mathrm{Al}$ & (Aluminum) & 100 & 500 & 10,000 \\
\hline $\mathrm{Am}$ & (Americium) & & 7000 & \\
\hline$B$ & (Boron) & 1 & 100 & 1000 \\
\hline $\mathrm{Be}$ & (Beryllium) & 100 & 100 & 2000 \\
\hline $\mathrm{Bi}$ & (Bismuth) & 10 & 100 & 1000 \\
\hline $\mathrm{C}$ & (Carbon) & 500 & 1000 & 5000 \\
\hline $\mathrm{Ca}$ & (Calcium) & 150 & 500 & 10,000 \\
\hline $\mathrm{Cd}$ & (Cadmium) & 5 & 10 & 1000 \\
\hline $\mathrm{Cl}^{\mathrm{a}}$ & (Chlorine) & $250^{a}$ & $250^{a}$ & 500 \\
\hline Co & (Cobalt) & 50 & 100 & 10,000 \\
\hline $\mathrm{Cr}$ & (Chromium) & 200 & 1000 & 1500 \\
\hline $\mathrm{Cu}$ & (Copper) & 100 & 100 & 500 \\
\hline Dy & (Dysprosium) & 0.5 & 1 & 1000 \\
\hline Eu & (Europium) & 0.5 & 1 & 1000 \\
\hline $\mathrm{Fa}$ & (Fluorine) & $250^{a}$ & $250^{a}$ & 500 \\
\hline $\mathrm{Fe}$ & (Iron) & 500 & 2000 & 3000 \\
\hline $\mathrm{Ga}$ & (Gallium) & 0.12 & 12,000 & 12,500 \\
\hline $\mathrm{Gd}$ & (Gadolinium) & 0.5 & 3 & 250 \\
\hline In & (Indium) & 20 & 20 & 1000 \\
\hline K & (Potassium) & 100 & 300 & 10,000 \\
\hline $\mathrm{Li}$ & (Lithium) & 100 & 400 & 10,000 \\
\hline $\mathrm{Mg}$ & (Magnesium) & 200 & 500 & 10,000 \\
\hline $\mathrm{Mn}$ & (Manganese) & 100 & 100 & 1000 \\
\hline Mo & (Molybdenum) & 100 & 100 & 1000 \\
\hline $\mathrm{N}$ & (Nitrogen) & 300 & 400 & 400 \\
\hline $\mathrm{Na}$ & (Sodium) & 100 & 1000 & 10,000 \\
\hline $\mathrm{Nb}$ & (Niobium) & 50 & 100 & 3500 \\
\hline $\mathrm{Ni}$ & (Nickel) & 200 & 5000 & 12000 \\
\hline $\mathrm{Np}$ & (Neptunium) & & 500 & \\
\hline$P b$ & (Phosphorus) & $250^{b}$ & 200 & 1000 \\
\hline $\mathrm{Pb}$ & (Lead) & 100 & 200 & 1000 \\
\hline$S^{b}$ & (Sulfur) & $250^{b}$ & 250 & 1000 \\
\hline $\mathrm{Si}$ & (Silicon) & 150 & 200 & 200 \\
\hline Sm & (Samarium) & 2 & 2 & 1000 \\
\hline Sn & (Tin) & 100 & 100 & 2500 \\
\hline $\mathrm{Ta}$ & (Tantalum) & 200 & 200 & 500 \\
\hline Th & (Thorium) & 50 & 100 & 100 \\
\hline $\mathrm{Ti}$ & (Titanium) & 100 & 100 & 2500 \\
\hline$U$ & (Uranium) & 100 & 5000 & \\
\hline V & (Vanadium) & 5 & 300 & 2500 \\
\hline W & (Tungsten) & 100 & 200 & 2500 \\
\hline $\mathrm{Zn}$ & (Zinc) & 100 & 150 & 1000 \\
\hline $\mathrm{Zr}$ & (Zirconium) & 50 & 50 & 1000 \\
\hline
\end{tabular}

a Limits for $\mathrm{F}$ and $\mathrm{Cl}$ are $\mathrm{F}+\mathrm{Cl}<250$.

${ }^{b}$ Limits for $\mathrm{P}$ and $\mathrm{S}$ are $\mathrm{P}+\mathrm{S}<250$ for Column $\mathrm{B}$. 


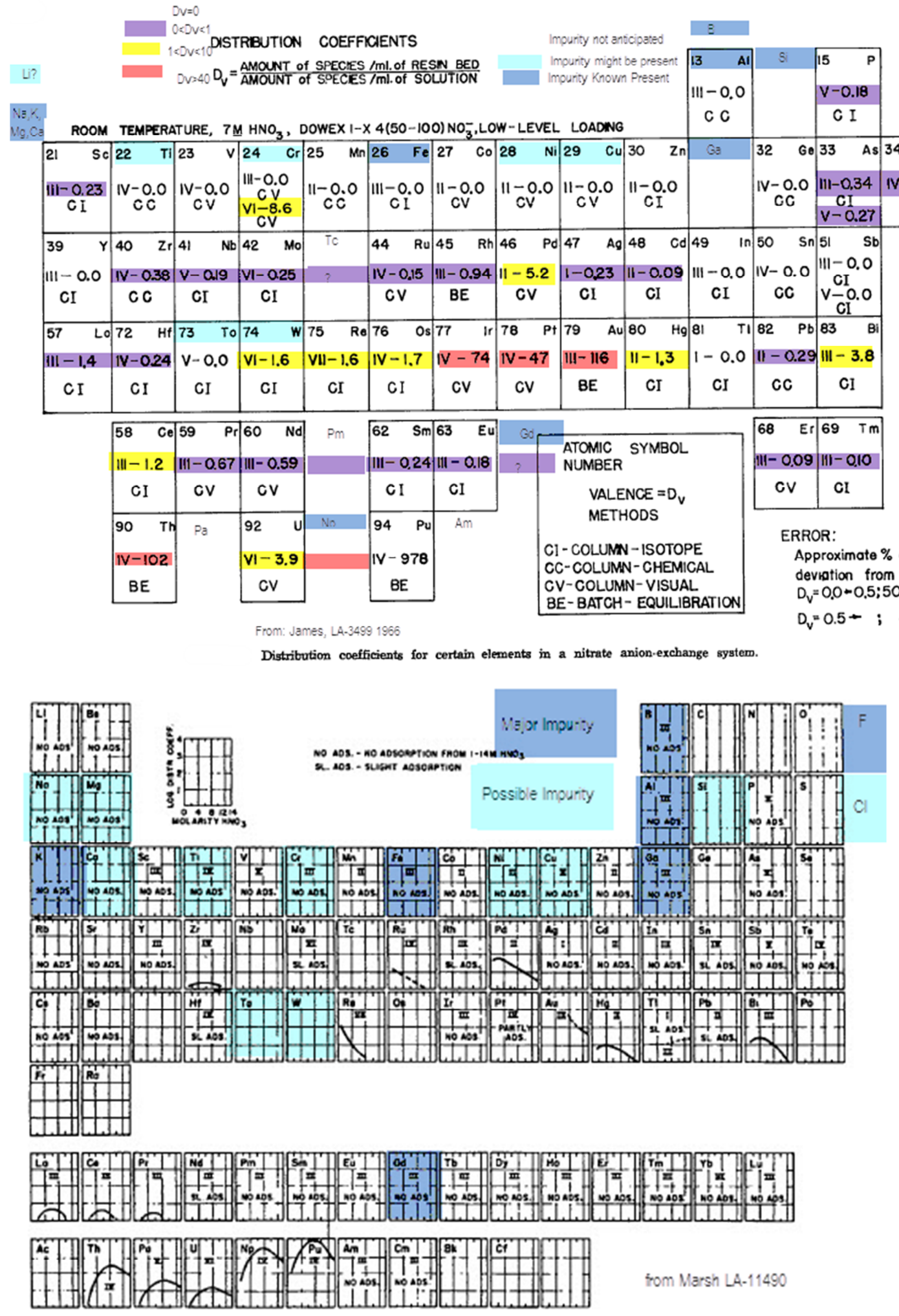

Figure 1. Distribution Coefficients in a Nitrate Anion Exchange System with Expected Impurities in HB-Line Process. 
Table 2. Process Scaling: HB-Line Column vs SRNL Ce and Pu Columns.

\begin{tabular}{|c|c|c|c|c|c|c|c|c|c|}
\hline & & & Recon- & Feed & Decont & lation & Elution & & \\
\hline & & $\mathrm{Pu}$ (g/batch) & & 1200 & & & & & \\
\hline & & $\mathrm{Pu}(\mathrm{g} / \mathrm{l})$ & & 4.5 & & & & & \\
\hline & & HNO3 (M) & 8 & 8 & 8 & 8 & 0.35 & & \\
\hline 294.2 & $\mathrm{~cm}^{2}$ & HB-Line & up & up & up & up & down & & \\
\hline 68.58 & $\mathrm{~cm}$ & Flow (L/min) & 1.4 & 1.1 & 1.1 & 2 & 0.7 & & \\
\hline & & $\mathrm{v}\left(\mathrm{mL} / \mathrm{min} / \mathrm{cm}^{2}\right)$ & 4.8 & 3.7 & 3.7 & 6.8 & 2.4 & & \\
\hline 20.2 & L & Volume (L) & 30 & 260 & 40 & 160 & 60 & & \\
\hline & & Time (min) & 21 & 236 & 36 & 80 & 86 & 7.7 & $\mathrm{~h}$ tota \\
\hline & & BV & 1.5 & 13.0 & 2.0 & 8.0 & 3.0 & & \\
\hline & & $\mathrm{mgs} \mathrm{Pu} / \mathrm{min} / \mathrm{cm}^{2}$ & & 17 & & & & & \\
\hline 2.835 & $\mathrm{~cm}^{2}$ & SRNL Hood -Ce & up & up & up & up & down & & \\
\hline 68.58 & $\mathrm{~cm}$ & Flow (mL/min) & 20 & 10.6 & 10.6 & 19.3 & 6.8 & & \\
\hline 1.90 & $\mathrm{~cm}$ & $\mathrm{v}\left(\mathrm{mL} / \mathrm{min} / \mathrm{cm}^{2}\right)$ & 7.1 & 3.7 & 3.7 & 6.8 & 2.4 & & \\
\hline 194.44 & CC & Volume (mL) & 200 & 1964 & 388 & 3492 & 450 & & \\
\hline & & Time (min) & 10 & 185 & 37 & 181 & 66 & 8.0 & h total \\
\hline & & BV & 1.0 & 10.1 & 2.0 & 18.0 & 2.3 & & \\
\hline & & $\mathrm{mgs} \mathrm{Pu} / \mathrm{min} / \mathrm{cm}^{2}$ & & 19 & & & & & \\
\hline 1.247 & $\mathrm{~cm}^{2}$ & SPNL Glovebox -Pu & up & up & up & up & down & & \\
\hline 68.58 & $\mathrm{~cm}$ & Flow (mL/min) & 10 & 4.5 & 4.5 & 8.5 & 3 & & \\
\hline 1.26 & $\mathrm{~cm}$ & $\mathrm{v}\left(\mathrm{mL} / \mathrm{min} / \mathrm{cm}^{2}\right)$ & 8.0 & 3.6 & 3.6 & 6.8 & 2.4 & & \\
\hline 85.512 & cc & Volume (mL) & 100 & 1000 & 172 & 688 & 260 & & \\
\hline & & Time (min) & 10 & 222 & 38 & 81 & 87 & 7.3 & $\mathrm{~h}$ total \\
\hline & & BV & 1.2 & 11.7 & 2.0 & 8.0 & 3.0 & & \\
\hline & & $\mathrm{mgs} \mathrm{Pu} / \mathrm{min} / \mathrm{cm}^{2}$ & & 18 & & & & & \\
\hline
\end{tabular}

Note: Up and down designates flow direction through resin bed 


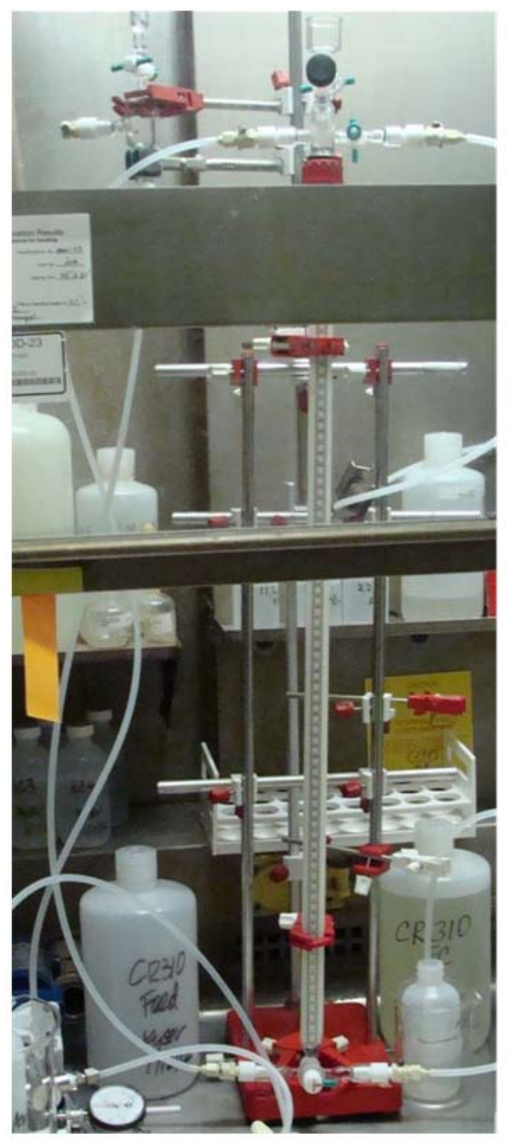

Figure 2a. Assembled Column for Non-Radioactive DF Experiments.

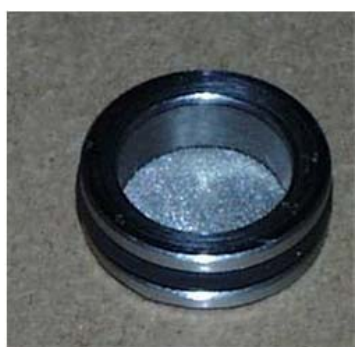

Figure $2 \mathrm{~b}$ Screen used to Retain Resin Bed. 


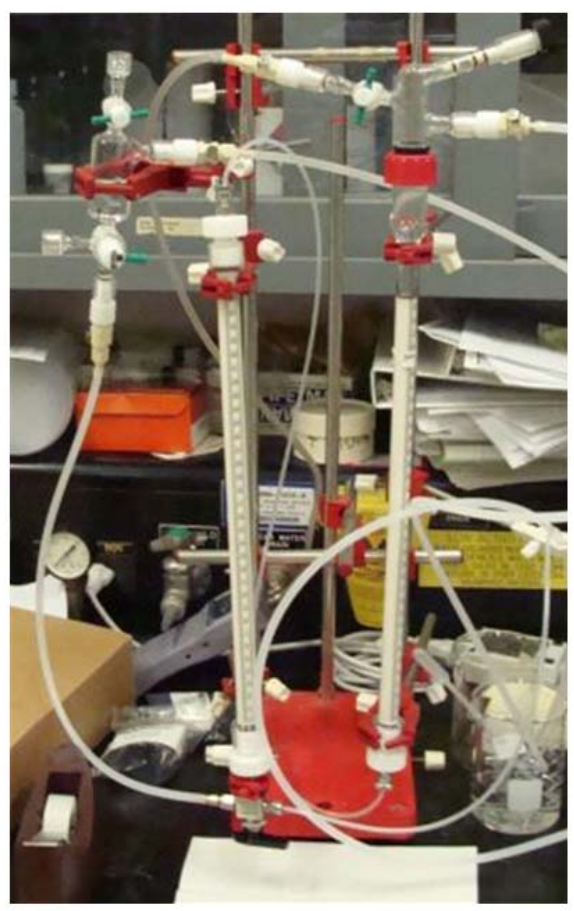

Figure 3. Assembled Column for Glovebox DF Experiments. 


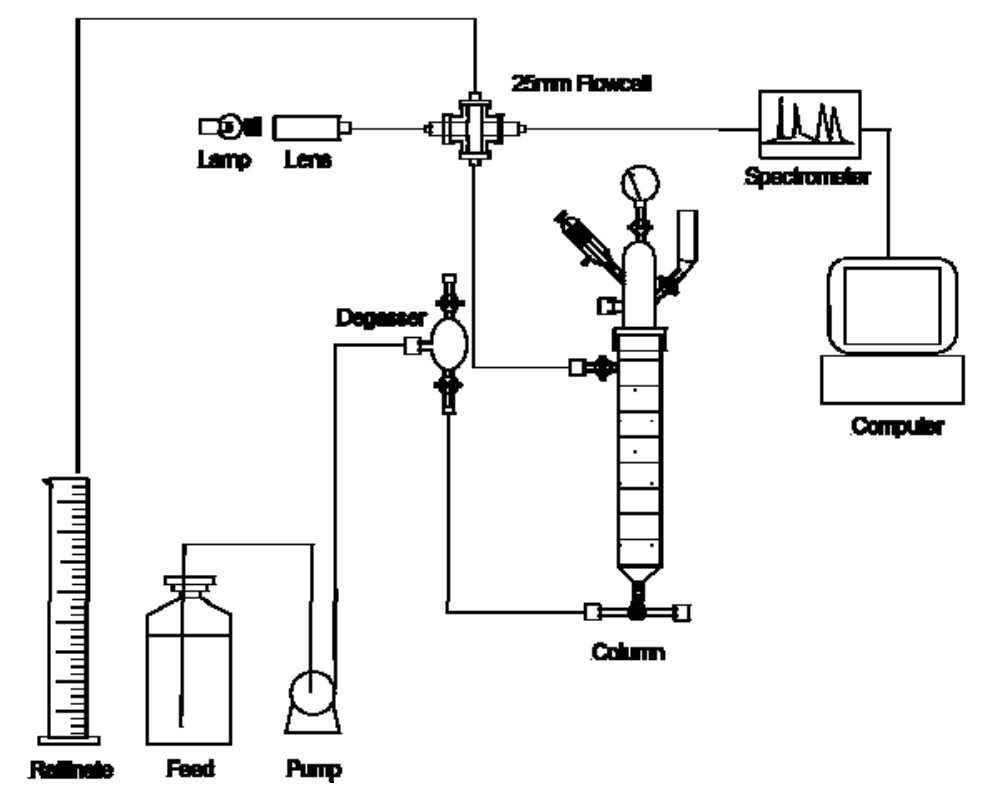

Figure 4. Up-flow Load/Wash Experimental Setup.

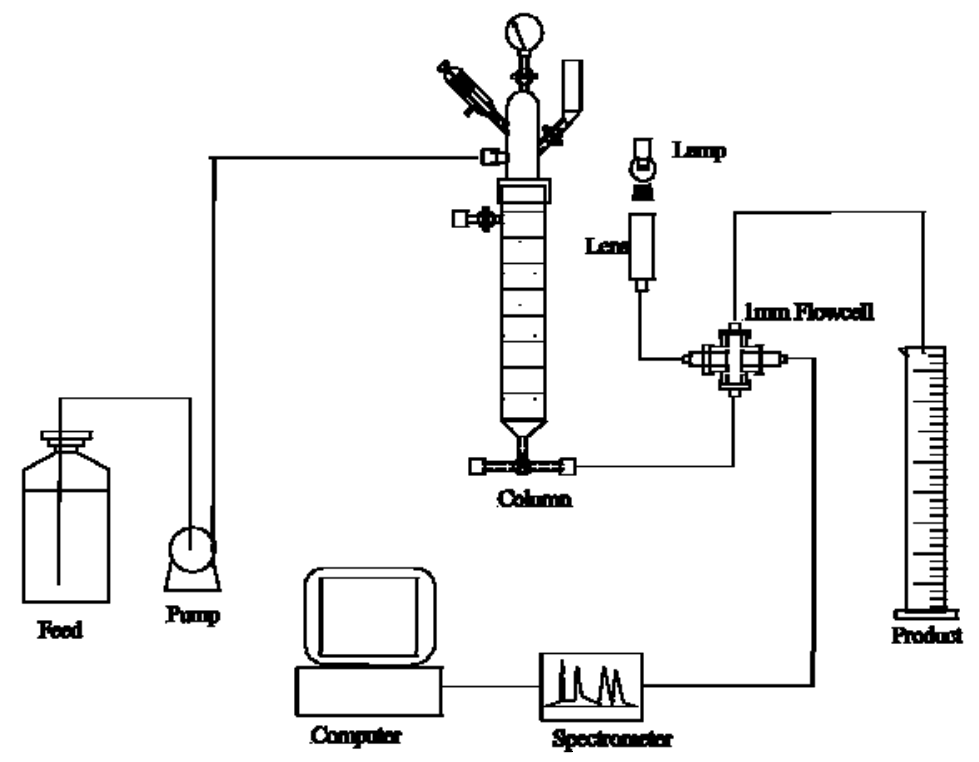

Figure 5. Elution Experimental Setup. 
Table 3. Impurities used for Anion Exchange Testing.

\begin{tabular}{|c|c|c|c|c|}
\hline M & $g / L$ & $\mu \mathrm{g} / \mathrm{g} \mathrm{Pu}$ & $\begin{array}{c}\text { Chemical } \\
\text { Component }\end{array}$ & \\
\hline & & & $\mathrm{Ag}$ & Little or no data available. Did not test \\
\hline \multirow[t]{3}{*}{0.2} & 5.4 & 1349075 & $\mathrm{Al}$ & Will add in process \\
\hline & & & $\mathrm{Am}$ & Pu Daughter product, grows in over time \\
\hline & & & As & No spec \\
\hline \multirow[t]{5}{*}{0.0925} & 1 & 250000 & $\mathrm{~B}$ & May add in process \\
\hline & & & $\mathrm{Ba}$ & No spec \\
\hline & & & $\mathrm{Be}$ & Not present in concentrations above Column B limit \\
\hline & & & $\mathrm{Bi}$ & Some adsorption onto IX, but not very soluble \\
\hline & & & C & Will add downstream in oxalate precipitation \\
\hline \multirow[t]{2}{*}{0.0025} & 0.1 & 25000 & $\mathrm{Ca}$ & Mostly below Column B Limit \\
\hline & & & $\mathrm{Cd}$ & Little or no data available. Did not test \\
\hline \multirow[t]{7}{*}{0.001} & 0.1 & 24000 & $\mathrm{Ce}$ & No spec, some absorption by IX, DF Np 15. Surrogate for Pu. \\
\hline & & & $\mathrm{Cl}$ & Present as impuriity, Unclear on concentration. Test in Precipitation only. \\
\hline & & & Co & Little or no data available. Did not test \\
\hline & & & $\mathrm{Cr}$ & Not present in concentrations above Column B limit \\
\hline & & & $\mathrm{Cu}$ & Mostly below Column B Limit \\
\hline & & & Dy & Little or no data available. Did not test \\
\hline & & & Eu & Little or no data available. Did not test \\
\hline 0.1 & 1.9 & 474960 & $\mathrm{~F}$ & Will add in process, \\
\hline 0.05 & 2.8 & 698088 & $\mathrm{Fe}$ & Will add in process, \\
\hline 0.0011 & 0.1 & 20000 & $\mathrm{Ga}$ & Present in Pu metal \\
\hline \multirow[t]{3}{*}{0.0025} & 0.4 & 100000 & $\mathrm{Gd}$ & May add in process \\
\hline & & & $\mathrm{Hf}$ & No spec \\
\hline & & & $\ln$ & Little or no data available. Did not test \\
\hline \multirow[t]{2}{*}{0.1} & 3.9 & 977550 & $\mathrm{~K}$ & Will add in process, \\
\hline & & & La & No spec \\
\hline 0.0144 & 0.1 & 25000 & $\mathrm{Li}$ & Somewhat high, not high in DE analysis or MIS \\
\hline 0.0041 & 0.1 & 25000 & $\mathrm{Mg}$ & Mostly below Column B Limit \\
\hline \multirow[t]{3}{*}{0.0018} & 0.1 & 25000 & $\mathrm{Mn}$ & Not present in concentrations above Column B limit, Np DF 300k in lab \\
\hline & & & Mo & Mostly below Column B Limit \\
\hline & & & $\mathrm{N}$ & Little or no data available. Did not test \\
\hline \multirow[t]{6}{*}{0.0043} & 0.1 & 25000 & $\mathrm{Na}$ & DF 14000 for Np process \\
\hline & & & $\mathrm{Nb}$ & Little or no data available. Did not test \\
\hline & & & $\mathrm{Ni}$ & Corrosion product, Observed Np Process DF of 400 \\
\hline & & & $\mathrm{Np}$ & Isolated contaminated materials, Known IX problems \\
\hline & & & $P$ & Little or no data available. Did not test \\
\hline & & & $\mathrm{Pb}$ & Not present in concentrations above Column B limit \\
\hline \multirow[t]{2}{*}{0.0167} & 4 & 1000000 & $\mathrm{Pu}$ & \\
\hline & & & S & Present in Lab Tests as FS. Not present in process. \\
\hline 0.0036 & 0.1 & 25000 & Si & Mostly below Column B Limit, but Si is endemic \\
\hline \multirow[t]{7}{*}{0.001} & 0.1 & 22000 & Sm & Not present in process but added for comparison to Gd. \\
\hline & & & Sn & Not present in concentrations above Column B limit \\
\hline & & & $\mathrm{Ta}$ & Not present in concentrations above Column B limit \\
\hline & & & Th & No data available, Known problem IX \\
\hline & & & $\mathrm{Ti}$ & Not present in concentrations above Column B limit \\
\hline & & & U & limited data, DF= 500 in HB-Line Np Process \\
\hline & & & V & Col B limit low, speciation complicated \\
\hline \multirow[t]{2}{*}{0.0005} & 0.1 & 25000 & W & Mostly below Column B Limit, anionic species possible \\
\hline & & & Y & Not present in concentrations above Column B limit \\
\hline \multirow[t]{2}{*}{0.0015} & 0.1 & 25000 & $\mathrm{Zn}$ & DF 400 in Np Process \\
\hline & & & $\mathrm{Zr}$ & Not present in concentrations above Column B limit \\
\hline
\end{tabular}


Table 4. Feed Preparation for Cr310, Cr311, Cr313 and Cr314 Experiments.

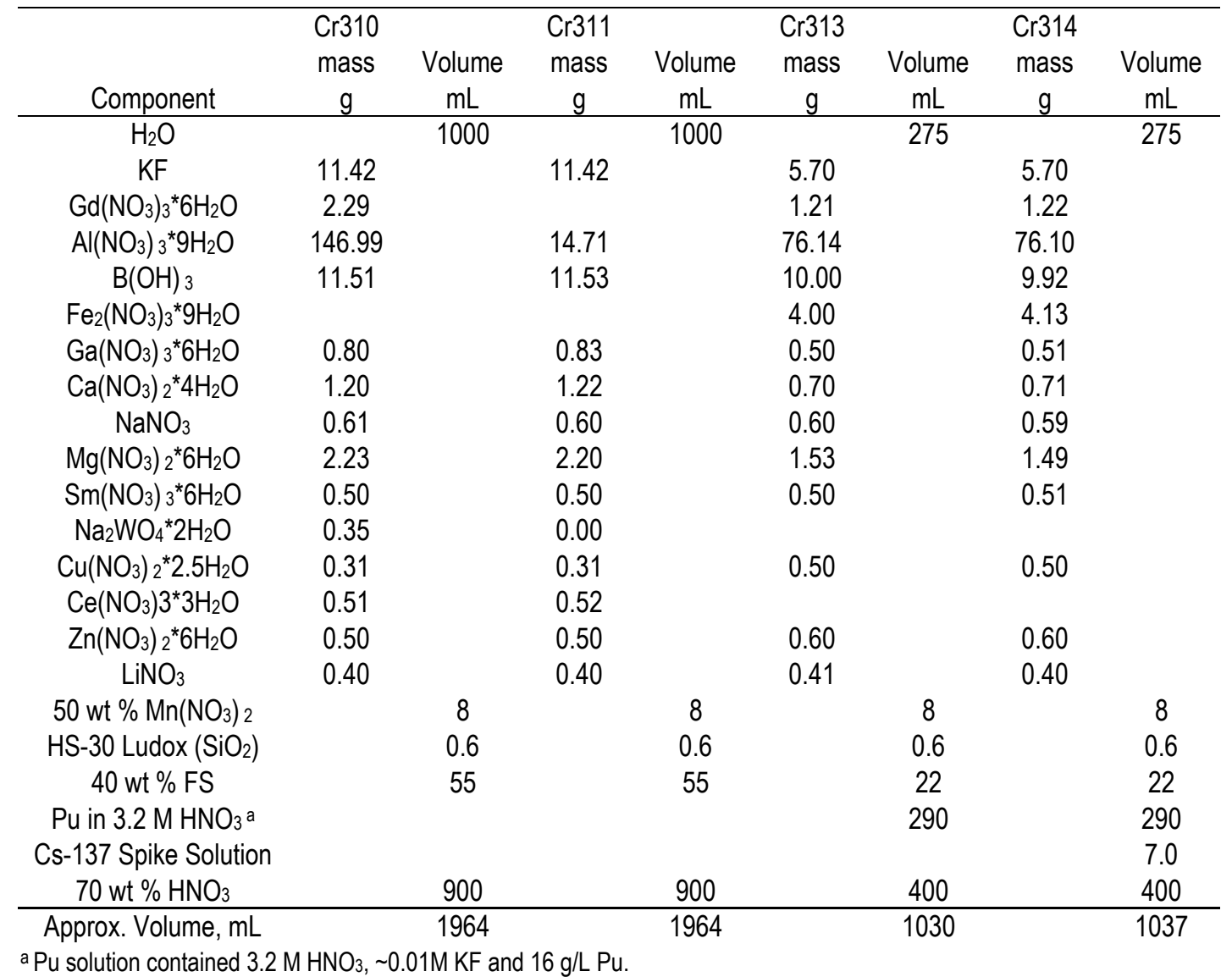


Table 5a. Feed Analysis for Cr310 and Cr311 Experiments.

\begin{tabular}{|c|c|c|c|c|c|c|c|}
\hline \multirow[b]{2}{*}{ Element } & \multicolumn{3}{|c|}{ Cr310 } & \multicolumn{3}{|c|}{$\mathrm{Cr} 311$} & \multirow[b]{2}{*}{ Method } \\
\hline & $\mathrm{mg} / \mathrm{L}$ & $\mathrm{mM}$ & $\mu \mathrm{g} / \mathrm{g} \mathrm{Pu}$ & $\mathrm{mg} / \mathrm{L}$ & $\mathrm{mM}$ & $\mu \mathrm{g} / \mathrm{g} \mathrm{Pu}$ & \\
\hline AD Sample ID & $3-295988$ & & & $3-296169$ & & & \\
\hline $\mathrm{Pu}$ & 4000 & 17 & & 4000 & 17 & & Assumed \\
\hline Nitrate & 490000 & 7903 & 122500000 & 469000 & 7564 & 117250000 & IC \\
\hline $\mathrm{Al}$ & 5850 & 217 & 1460000 & 589 & 22 & 147000 & ICPES \\
\hline$S$ & 4500 & 140 & 1130000 & 5080 & 158 & 1270000 & ICPES \\
\hline B & 1050 & 97 & 263000 & 1100 & 102 & 275000 & ICPES \\
\hline K & 3530 & 90 & 883000 & 3790 & 97 & 948000 & ICPES \\
\hline $\mathrm{F}$ & 1530 & 81 & 383000 & 1570 & 83 & 393000 & IC \\
\hline $\mathrm{Fe}$ & 3430 & 61 & 858000 & 3600 & 64 & 900000 & ICPES \\
\hline $\mathrm{Mn}$ & 945 & 17 & 236000 & 1110 & 20 & 278000 & ICPES \\
\hline $\mathrm{Na}$ & 121 & 5.3 & 30300 & 97.3 & 4 & 24300 & ICPES \\
\hline $\mathrm{Mg}$ & 122 & 5.0 & 30500 & 116 & 4.8 & 29000 & ICPES \\
\hline $\mathrm{Ca}$ & 119 & 3.0 & 29800 & 120 & 3.0 & 30000 & ICPES \\
\hline $\mathrm{Gd}$ & 406 & 2.6 & 102000 & $<0.34$ & 0.002 & 86 & ICPES \\
\hline Gd-160 & 399 & 2.5 & 99900 & & & & ICPMS \\
\hline $\mathrm{Si}$ & 41.9 & 1.5 & 10500 & 23.5 & 0.8 & 5880 & ICPES \\
\hline Ga-69 & 67 & 1.0 & 16800 & 11 & 0.2 & 2780 & ICPMS \\
\hline $\mathrm{Zn}$ & 59.8 & 0.9 & 15000 & 59.7 & 0.9 & 14900 & ICPES \\
\hline $\mathrm{Cu}$ & 42.3 & 0.7 & 10600 & 48.6 & 0.8 & 12200 & ICPES \\
\hline Sm-149 & 87 & 0.6 & 21700 & 86 & 0.6 & 21600 & ICPMS \\
\hline W-184 & 59 & 0.3 & 14700 & 0 & & & \\
\hline $\mathrm{Ce}$ & 37.9 & 0.3 & 9480 & 54.4 & 0.4 & 13600 & ICPES \\
\hline Ce-140 & 41 & 0.3 & 10100 & 57 & 0.4 & 14200 & ICPMS \\
\hline \multicolumn{8}{|l|}{$\mathrm{Am}$} \\
\hline $\mathrm{Li}$ & 1.64 & 0.2 & 410 & 15.1 & 2.2 & 3780 & ICPES \\
\hline $\mathrm{Ni}$ & 1.74 & 0.03 & 435 & 0.938 & 0.02 & 235 & ICPES \\
\hline $\mathrm{Pb}$ & $<7.16$ & & 1790 & $<1.15$ & & 288 & ICPES \\
\hline Sn & $<5.61$ & & 1400 & $<0.9$ & & 225 & ICPES \\
\hline Mo & $<2.25$ & & 563 & $<0.99$ & & 247 & ICPES \\
\hline Co & $<0.85$ & & 213 & $<0.85$ & & 213 & ICPES \\
\hline $\mathrm{Cr}$ & $<0.82$ & & 205 & $<0.82$ & & 205 & ICPES \\
\hline $\mathrm{Cd}$ & $<0.64$ & & 160 & $<0.102$ & & 26 & ICPES \\
\hline V & $<0.47$ & & 118 & $<0.08$ & & 19 & ICPES \\
\hline $\mathrm{Ti}$ & $<0.13$ & & 33 & $<0.021$ & & 5 & ICPES \\
\hline $\mathrm{Be}$ & $<0.12$ & & 30 & $<0.06$ & & $<15$ & ICPES \\
\hline
\end{tabular}

Note: Pu was not present in $\mathrm{Cr} 310$ or $\mathrm{Cr} 311$ but impurities are calculated based on an assumed concentration. 
Table 5b. Feed Analysis for Cr313 and Cr314 Experiments.

\begin{tabular}{|c|c|c|c|c|c|c|c|}
\hline & & $\mathrm{Cr} 313$ & & & Cr314 & & \\
\hline Element & $\mathrm{mg} / \mathrm{L}$ & $\mathrm{mM}$ & $u g / g P u$ & $\mathrm{mg} / \mathrm{L}$ & $\mathrm{mM}$ & $u g / g \mathrm{Pu}$ & Method \\
\hline AD Sample ID & 300297549 & & & 300297555 & & & \\
\hline $\mathrm{Pu}$ & 6026 & 25 & & 5638 & 24 & & alpha/gamma \\
\hline Nitrate & 431000 & 6951 & 76400000 & 419000 & 6758 & 74300000 & IC \\
\hline $\mathrm{Al}$ & 5390 & 200 & 956000 & 5600 & 208 & 993000 & ICPES \\
\hline$S$ & 3630 & 113 & 644000 & 3880 & 121 & 688000 & ICPES \\
\hline B & 1630 & 151 & 289000 & 1770 & 164 & 314000 & ICPES \\
\hline K & 3480 & 89 & 617000 & 3620 & 93 & 642000 & ICPES \\
\hline $\mathrm{F}$ & 1570 & 83 & 278000 & 1600 & 84 & 284000 & IC \\
\hline $\mathrm{Fe}$ & 3180 & 57 & 564000 & 3440 & 62 & 610000 & ICPES \\
\hline $\mathrm{Mn}$ & 1350 & 25 & 239000 & 1540 & 28 & 273000 & ICPES \\
\hline $\mathrm{Na}$ & 176 & 7.7 & 31200 & 164 & 7.1 & 29100 & ICPES \\
\hline $\mathrm{Mg}$ & 141 & 5.8 & 25000 & 242 & 10.0 & 42900 & ICPES \\
\hline $\mathrm{Ca}$ & 111 & 2.8 & 19700 & 118 & 2.9 & 20900 & ICPES \\
\hline $\mathrm{Gd}$ & 372 & 2.4 & 66000 & 389 & 2.5 & 69000 & ICPES \\
\hline Gd-160 & 379 & 2.4 & 67200 & 398 & 2.5 & 70700 & ICPMS \\
\hline $\mathrm{Si}$ & 59.2 & 2.1 & 10500 & 77.1 & 2.7 & 13700 & ICPES \\
\hline Ga-69 & 77 & 1.1 & 13700 & 83 & 1.2 & 14800 & ICPMS \\
\hline $\mathrm{Zn}$ & 135 & 2.1 & 23900 & 128 & 2.0 & 22700 & ICPES \\
\hline $\mathrm{Cu}$ & 115 & 1.8 & 20400 & 134 & 2.1 & 23800 & ICPES \\
\hline Sm-149 & 153 & 1.0 & 27100 & 192 & 1.3 & 34100 & ICPMS \\
\hline \multicolumn{8}{|l|}{ W-184 } \\
\hline $\mathrm{Ce}$ & 0.965 & 0.01 & 171 & $<0.965$ & & 171 & ICPES \\
\hline \multicolumn{8}{|l|}{ Ce-140 } \\
\hline $\mathrm{Am}$ & 5.9 & 0.02 & 1040 & 5.8 & 0.02 & 1030 & alpha/gamma \\
\hline $\mathrm{Li}$ & 23 & 3.33 & 4100 & 37 & 5.32 & 6540 & ICPES \\
\hline $\mathrm{Ni}$ & 1.6 & & 280 & 0.26 & & 45 & ICPES \\
\hline $\mathrm{Pb}$ & $<7.16$ & & 1270 & $<7.16$ & & 1270 & ICPES \\
\hline Sn & & & 0 & $<5.61$ & & 995 & ICPES \\
\hline Mo & $<1.48$ & & 260 & $<0.99$ & & 175 & ICPES \\
\hline Co & $<0.85$ & & 151 & $<0.85$ & & 151 & ICPES \\
\hline $\mathrm{Cr}$ & $<1.02$ & & 181 & $<1.02$ & & 181 & ICPES \\
\hline $\mathrm{Cd}$ & $<0.102$ & & 18 & $<0.102$ & & 18 & ICPES \\
\hline V & $<0.39$ & & 69 & $<0.39$ & & 69 & ICPES \\
\hline $\mathrm{Ti}$ & $<0.13$ & & 23 & $<0.13$ & & 23 & ICPES \\
\hline $\mathrm{Be}$ & $<0.06$ & & 11 & $<0.06$ & & 11 & ICPES \\
\hline
\end{tabular}

Note: Raffinate sample analysis from $\mathrm{Cr} 313$ reported in place of feed analysis. Concentrations diluted by $\sim 6 \%$ based on $\mathrm{Cr} 314$ results. 
Table 6. Targeted and Actual Flowrates.

$\begin{array}{cccccccc} & \begin{array}{c}\text { Target } \\ \mathrm{mL} / \mathrm{min}\end{array} & \begin{array}{c}\text { Cr-310 } \\ \text { Actual } \\ \mathrm{mL} / \mathrm{min}\end{array} & \begin{array}{c}\text { Cr-311 } \\ \text { Actual }\end{array} & \begin{array}{c}\text { Target } \\ \mathrm{mL} / \mathrm{min}\end{array} & \begin{array}{c}\text { Cr-313 } \\ \text { Actual }\end{array} & \begin{array}{c}\mathrm{Cr}-314 \\ \text { Actual }\end{array} \\ \begin{array}{ccc}\mathrm{mL} / \mathrm{min} \\ \text { Loading }\end{array} & 10.6 & 10.4 & 9.8 & & 4.5 & 5.3 & 4.4 \\ \text { WC1 Wash } & 10.6 & 10.1 & 7.6 & & 4.5 & 5.1 & 4.1 \\ \text { WC2 Wash } & 10.6 & 11.2 & 10.4 & & 8.5 & 8.4 & 7.6 \\ \text { WC3 Wash } & 19.3 & 17.4 & 19.5 & & 8.5 & 9.1 & 6.0 \\ \text { WC4 Wash } & 19.3 & 17.2 & 18.0 & & 8.5 & 8.4 & 8.1 \\ \text { WC5 Wash } & 19.3 & 19.3 & 21.6 & & 8.5 & 7.5 & 8.3 \\ \text { WC6 Wash } & 19.3 & 18.9 & 21.1 & & 8.5 & & 9.4 \\ \text { WC7-10 Wash } & 19.3 & 20.0 & 18.0 & \text { WC7 } & 8.5 & & 7.6 \\ \text { WC11-15 Wash } & 19.3 & 19.8 & 19.4 & \text { WC8 } & 8.5 & 9.2 & 8.3 \\ \text { WC16-20 Wash } & 19.3 & 19.2 & 20.9 & \text { WC9 } & 8.5 & 8.6 & 8.1 \\ \text { Displacement }{ }^{2} & 6.8 & 2.5 \mathrm{~b} & 2.4 & & 3.0 & 2.9 & 1.8 \\ \text { Hearts } & 6.8 & 1.5 \mathrm{~b} & 2.6 & & 3.0 & 3.4 & 3.0 \\ \text { Tails } & 6.8 & 1.5 \mathrm{~b} & 2.8 & & 3.0 & 3.2 & 3.0 \\ \text { Avg. Wash 1-2 } & 10.6 & 10.7 & 8.8 & & & & \\ \text { Avg. Wash 3-20 } & 19.3 & 19.3 & 19.6 & \text { WC2-9 } & 8.5 & 8.7 & 7.8 \\ \text { Avg. Elution } & 6.8 & 1.8 & 2.6 & & 3.0 & 3.2 & 2.6\end{array}$

a $\mathrm{Cr} 310$ Displacement volume was increased by the drainage of column head solution into Displacement bottle.

${ }^{b}$ Lower than target flow rate for elution in $\mathrm{Cr} 310$ resulted in lower than targeted volumes for Hearts and Tails solutions. 
Table 7. Analyzed Impurity Concentrations in Hearts Samples.

\begin{tabular}{cccccc}
\hline Element & $\begin{array}{c}\text { Col A } \\
\text { ug/g Pu }\end{array}$ & $\begin{array}{c}\text { Cr310 a } \\
\text { ug/g Pu }\end{array}$ & $\begin{array}{c}\text { Cr311 a } \\
\text { ug/gPu }\end{array}$ & $\begin{array}{c}\text { Cr313 } \\
\text { ug } / g ~ P u\end{array}$ & $\begin{array}{c}\text { Cr314 } \\
\text { ug } / g ~ P u\end{array}$ \\
\hline $\mathrm{Al}$ & 500 & 9.2 & 12.8 & 136 & 206 \\
$\mathrm{~B}$ & 100 & $<4.5$ & $<4.5$ & 129 & 153 \\
$\mathrm{Ca}$ & 500 & 5.1 & 4.5 & 61.8 & 119 \\
$\mathrm{Ga}-69$ & 12000 & 0.4 & $<0.12$ & 1.2 & 1.2 \\
$\mathrm{Gd}$ & 3 & $<6.9$ & $<6.9$ & 21.1 & 24.6 \\
$\mathrm{Gd}-160$ & 3 & 0.5 & 0.1 & 23.3 & 24.4 \\
$\mathrm{Fe}$ & 2000 & 2.8 & 3.0 & 10.2 & 75.0 \\
$\mathrm{~F}$ & 250 & $<2000$ & $<10,000$ & & \\
$\mathrm{~K}$ & 300 & $<96.2$ & $<96.2$ & 348 & 463 \\
$\mathrm{Li}$ & 400 & $<4.7$ & $<4.7$ & $<5.1$ & $<5.5$ \\
$\mathrm{Mg}$ & 500 & $<0.48$ & 0.50 & $<0.52$ & 77.8 \\
$\mathrm{Mn}$ & 100 & $<0.67$ & 1.4 & 7.7 & 24.9 \\
$\mathrm{Na}$ & 1000 & $<17$ & $<17$ & $<92$ & $<100$ \\
$\mathrm{~S}$ & 250 & $<240$ & $<240$ & $<519$ & $<562$ \\
$\mathrm{Si}$ & 200 & $<14$ & $<14$ & 68.5 & 99.5 \\
$\mathrm{Sm}-149$ & 2 & 1.8 & 1.4 & 42.8 & 48.8 \\
$\mathrm{~W}-184$ & 200 & 1.0 & & & $<18$ \\
$\mathrm{Zn}$ & 150 & $<2.9$ & $<2.9$ & $<17$ & \\
\hline & & & & & \\
\hline
\end{tabular}

Note: Red background indicates impurity concentration above specification. Yellow indicates impurity concentration above $50 \%$ of specification. White indicates impurity concentration between $10 \%$ and $50 \%$ of specification. Green indicates impurity concentration below $10 \%$ of specification.

Note: Values from ICPMS are reported as elemental concentrations and have been corrected for natural abundance.

${ }^{a}$ For $\mathrm{Cr} 310$ and $\mathrm{Cr} 311$, a Pu product concentration of $50 \mathrm{~g} / \mathrm{L}$ was assumed.

${ }^{b} \mathrm{Na}$ values for $\mathrm{Cr} 313$ and $\mathrm{Cr} 314$ are analyzed with Pu present. Values for all other elements for $\mathrm{Cr} 313$ and $\mathrm{Cr} 314$ are analyzed after Pu has been removed. 
Table 8a. Impurity Material Balance for Cr310, Cr311 and Cr314 Column Runs.

\begin{tabular}{|c|c|c|c|c|c|c|c|c|c|c|c|c|}
\hline \multirow[b]{2}{*}{ Component } & \multicolumn{4}{|c|}{ Cr310 Material Balance } & \multicolumn{4}{|c|}{ Cr311 Material Balance } & \multicolumn{4}{|c|}{ Cr314 Material Balance } \\
\hline & $\begin{array}{l}\text { Effluent } \\
\%\end{array}$ & $\begin{array}{c}\text { Wash } \\
\%\end{array}$ & $\begin{array}{c}\text { Eluate } \\
\%\end{array}$ & $\begin{array}{c}\text { Overall } \\
\%\end{array}$ & $\begin{array}{c}\text { Effluent } \\
\%\end{array}$ & $\begin{array}{c}\text { Wash } \\
\%\end{array}$ & $\begin{array}{c}\text { Eluate } \\
\%\end{array}$ & $\begin{array}{c}\text { Overall } \\
\%\end{array}$ & $\begin{array}{c}\text { Effluent } \\
\%\end{array}$ & $\begin{array}{c}\text { Wash } \\
\%\end{array}$ & $\begin{array}{c}\text { Eluate } \\
\%\end{array}$ & $\begin{array}{c}\text { Overall } \\
\%\end{array}$ \\
\hline $\mathrm{Al}$ & 90.9 & 9.7 & 0.001 & 100.7 & 90.8 & 9.2 & 0.019 & 100.0 & 93.9 & 7.5 & 0.025 & 101.5 \\
\hline Am & & & & & & & & & 80.4 & 11.5 & 0.7 & 92.6 \\
\hline B & 90.1 & 10.4 & 0.004 & 100.5 & 88.4 & 11.1 & 0.006 & 99.4 & 93.8 & 8.0 & 0.071 & 101.8 \\
\hline $\mathrm{Ca}$ & 89.9 & 10.2 & 0.040 & 100.1 & 91.7 & 9.8 & 0.06 & 101.5 & 95.8 & 8.1 & 0.762 & 104.6 \\
\hline $\mathrm{Ce}$ & 7.9 & 68.8 & 5.02 & 81.7 & 11.7 & 66.7 & 10.3 & 88.7 & & & & \\
\hline Ce-140 & 10.5 & 76.9 & 8.3 & 95.6 & 11.4 & 73.7 & 9.4 & 94.4 & & & & \\
\hline Cs & & & & & & & & & 87.8 & 7.3 & 0.004 & 95.1 \\
\hline $\mathrm{Cu}$ & 90.8 & 10.3 & 0.04 & 101.1 & 91.6 & 9.6 & 0.06 & 101.2 & 92.5 & 8.5 & 0.180 & 101.2 \\
\hline $\mathrm{Fe}$ & 91.0 & 9.8 & 0.002 & 100.7 & 90.6 & 9.0 & 0.0023 & 99.5 & 93.9 & 7.6 & 0.018 & 101.5 \\
\hline Ga-69 & 92.2 & 9.6 & 0.003 & 101.8 & 93.9 & 9.6 & 0.010 & 103.5 & 96.4 & 8.7 & 0.030 & 105.2 \\
\hline Gd & 89.2 & 11.2 & 0.015 & 100.4 & & & & & 94.3 & 8.1 & 0.046 & 102.5 \\
\hline Gd-155 & 89.4 & 11.0 & 0.001 & 100.4 & 85.0 & 14.2 & 0.57 & 99.8 & 93.8 & 9.0 & 0.051 & 102.9 \\
\hline Gd-160 & 88.0 & 11.1 & 0.001 & 99.1 & 88.0 & 13.2 & 0.28 & 101.5 & 90.3 & 9.0 & 0.050 & 99.4 \\
\hline K & 90.1 & 10.2 & 0.029 & 100.3 & 90.2 & 9.4 & 0.035 & 99.7 & 93.4 & 7.7 & 0.120 & 101.2 \\
\hline $\mathrm{Li}$ & 99.4 & 43.9 & 2.5 & 145.8 & 91.4 & 10.9 & 0.4 & 102.8 & 94.3 & 8.2 & 0.185 & 102.7 \\
\hline $\mathrm{Mg}$ & 91.0 & 9.8 & 0.005 & 100.7 & 91.4 & 9.1 & 0.009 & 100.5 & 94.6 & 7.6 & 0.244 & 102.5 \\
\hline $\mathrm{Mn}$ & 91.1 & 9.9 & 0.001 & 101.0 & 89.8 & 9.1 & 0.0024 & 98.9 & 94.2 & 7.6 & 0.013 & 101.8 \\
\hline $\mathrm{Na}$ & 91.3 & 11.6 & 0.1 & 103.0 & 91.7 & 12.3 & 0.2 & 104.2 & 94.5 & 8.1 & 0.821 & 103.4 \\
\hline $\mathrm{Pu}$ & & & & & & & & & 0.03 & 1.1 & 96.2 & 97.3 \\
\hline$S$ & 90.7 & 10.7 & 0.046 & 101.4 & 89.6 & 10.0 & 0.066 & 99.6 & 93.3 & 7.4 & 0.151 & 100.8 \\
\hline $\mathrm{Si}$ & 13.6 & 5.4 & 0.29 & 19.3 & 103.8 & 66.3 & 0.9 & 171.1 & 34.1 & 3.5 & 1.273 & 38.9 \\
\hline Sm-149 & 83.6 & 15.2 & 0.007 & 98.8 & 82.3 & 13.7 & 0.013 & 96.0 & 85.5 & 9.5 & 0.203 & 95.2 \\
\hline W-184 & 20.5 & 2.1 & 0.051 & 22.6 & & & & & & & & \\
\hline $\mathrm{Zn}$ & 91.6 & 10.3 & 0.042 & 101.9 & 91.6 & 9.5 & 0.068 & 101.1 & 96.9 & 8.0 & 0.131 & 105.0 \\
\hline
\end{tabular}


Table 8b. Material Balance for Pu Column Experiment Cr313 (85cc Two Piece Column Reillex $\left.\mathrm{HPQ}^{\mathrm{TM}}\right)$.

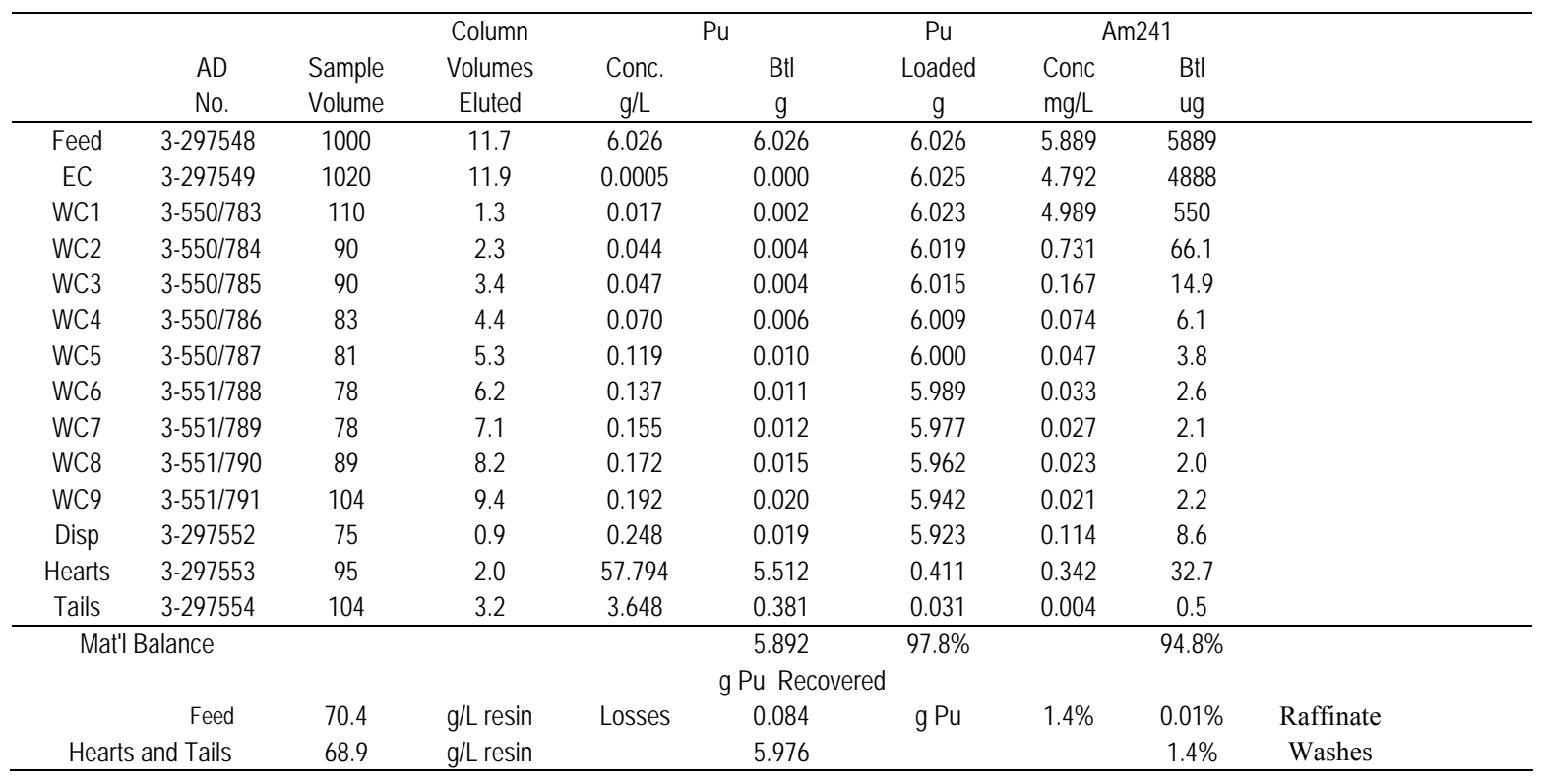

Table 8c. Material Balance for Pu Column Experiment Cr314 (85cc Two Piece Column Reillex $\mathrm{HPQ}^{\mathrm{TM}}$ ).

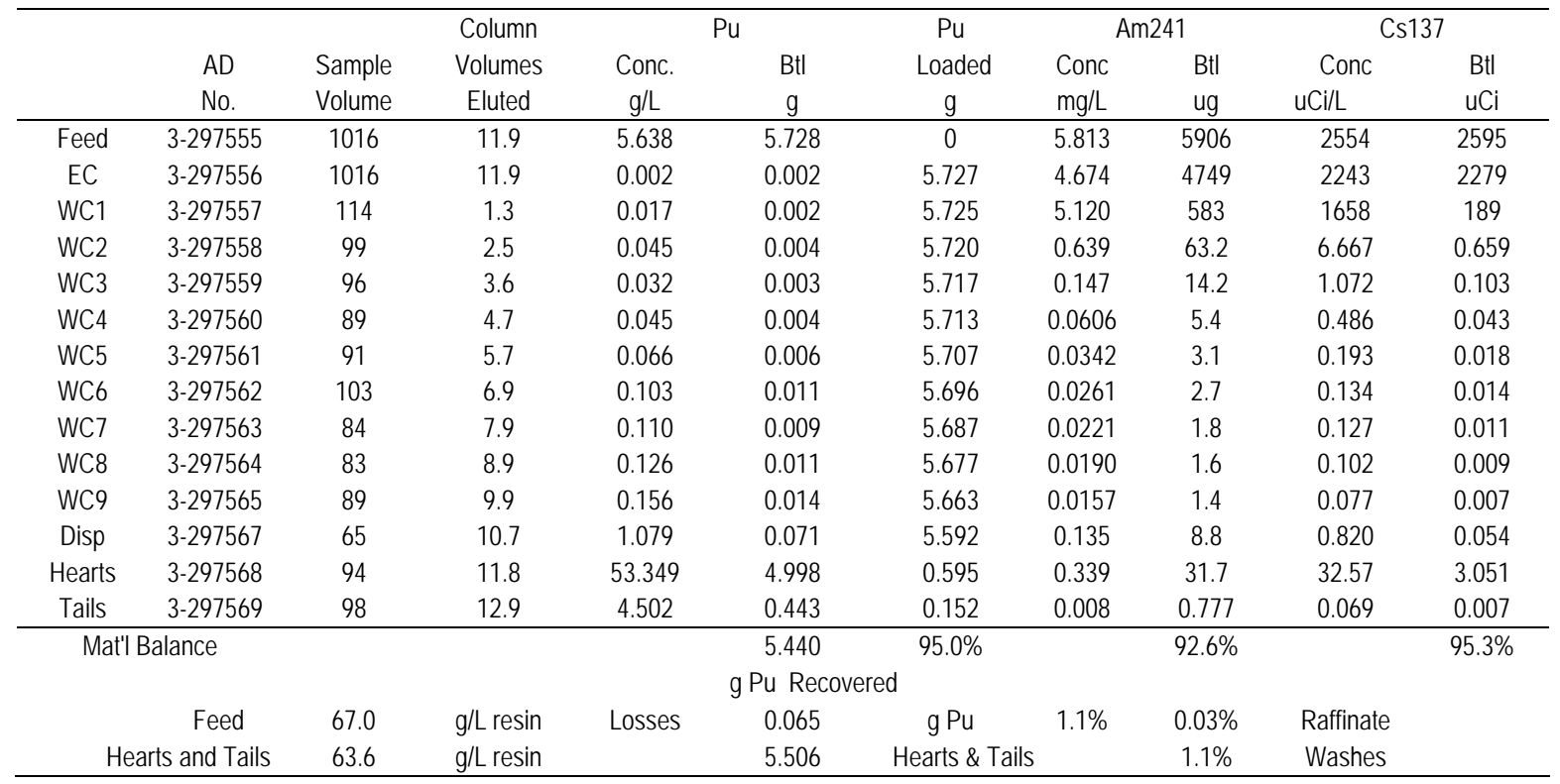


Table 9. Anion Exchange DF Observations.

\begin{tabular}{ccccc} 
& Cr310 & Cr311 & Cr313 & Cr314 \\
Al & 160000 & 12000 & 7000 & 4800 \\
Am-241 & & & 170 & 160 \\
$\mathrm{~B}$ & 58000 & 61000 & 2200 & 2100 \\
$\mathrm{Ca}$ & 5900 & 6700 & 320 & 180 \\
$\mathrm{Ce}$ & 13 & 12 & 8 & 8 \\
$\mathrm{Cu}$ & 5200 & 6000 & 1900 & 2100 \\
$\mathrm{Fe}$ & 310000 & 300000 & 55100 & 8100 \\
$\mathrm{Ga}-69$ & 38000 & 24000 & 12000 & 12000 \\
$\mathrm{Gd}$ & 15000 & 0 & 3100 & 2800 \\
$\mathrm{Gd}-160$ & 200000 & 860 & 2700 & 2900 \\
$\mathrm{~K}$ & 9200 & 9800 & 1800 & 1400 \\
$\mathrm{Li}$ & 90 & 810 & 800 & 1200 \\
$\mathrm{Mg}$ & 64000 & 58000 & 48000 & 550 \\
$\mathrm{Mn}$ & 350000 & 200000 & 31000 & 11000 \\
$\mathrm{Na}$ & 1800 & 1400 & 340 & 290 \\
$\mathrm{~S}$ & 4700 & 5300 & 1200 & 1200 \\
$\mathrm{Si}$ & 750 & 420 & 150 & 140 \\
$\mathrm{Sm}-149$ & 12000 & 15000 & 630 & 700 \\
W-184 & 14000 & \multicolumn{3}{c}{} \\
$\mathrm{Zn}$ & 5100 & 5100 & 1400 & 1200 \\
Note: DF calculated as the ratio of the impurity to & Pu in the feed solution divided by the \\
ratio of the impurity to Pu in the product solution. & &
\end{tabular}




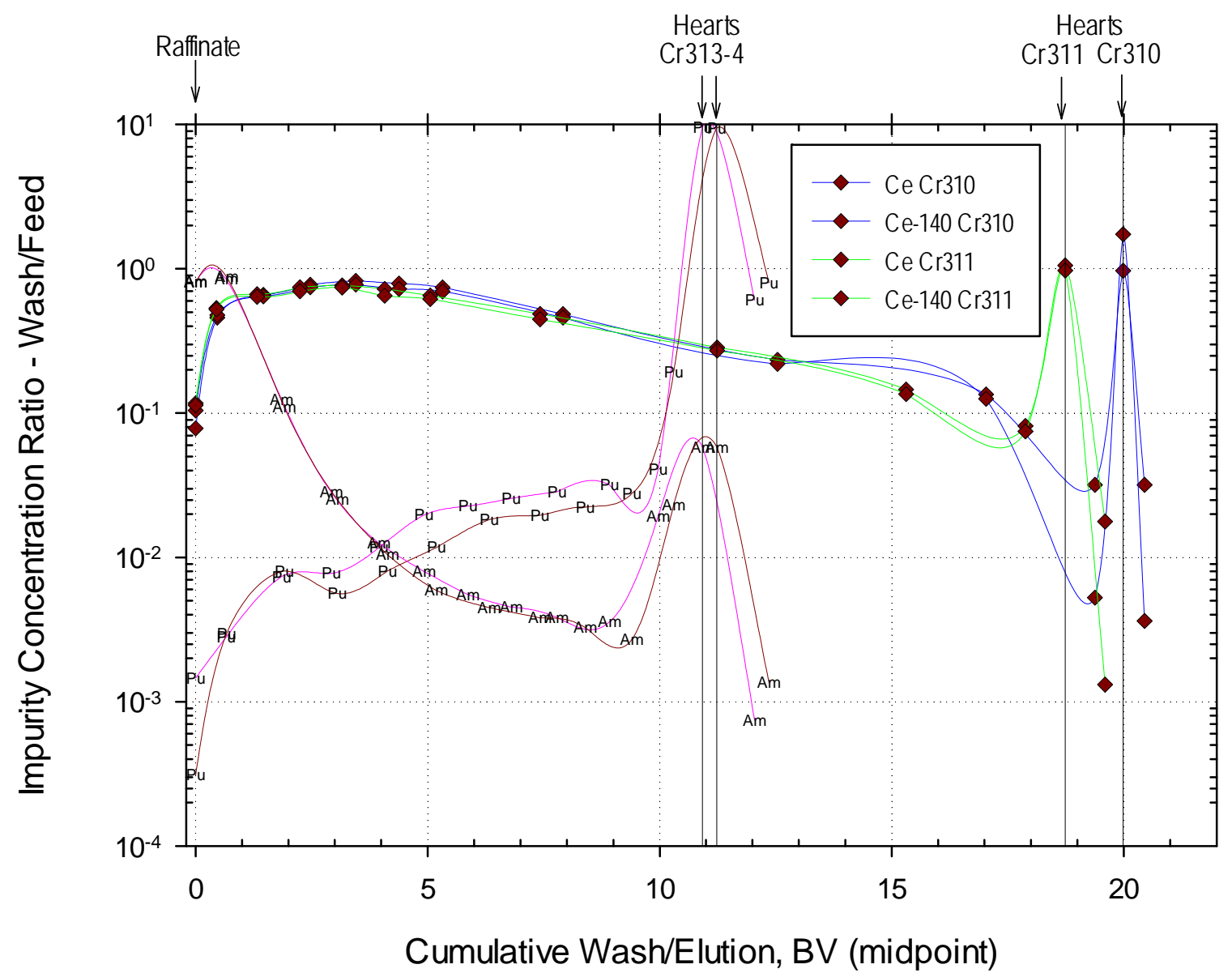

Note: Blue lines are $\mathrm{Cr} 310$, Green lines are $\mathrm{Cr} 311$, Pink lines are $\mathrm{Cr} 313$ and Dark red lines are $\mathrm{Cr} 314$ for all graphs.

Figure 6. $\mathrm{Ce}, \mathrm{Pu}$, and $\mathrm{Am}$ Wash-Elution Profile. 


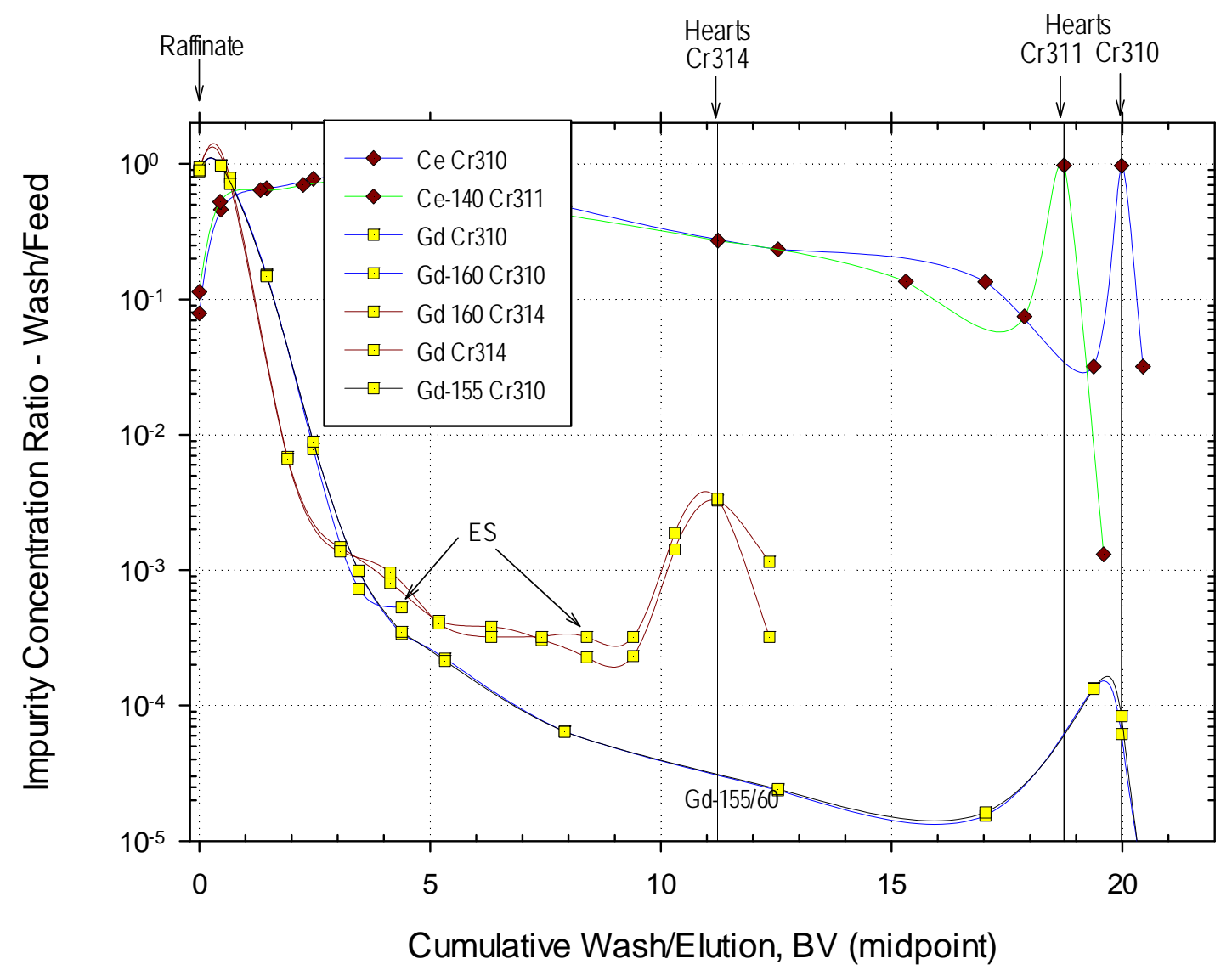

Figure 7. Gd and Ce Wash-Elution Profiles. 


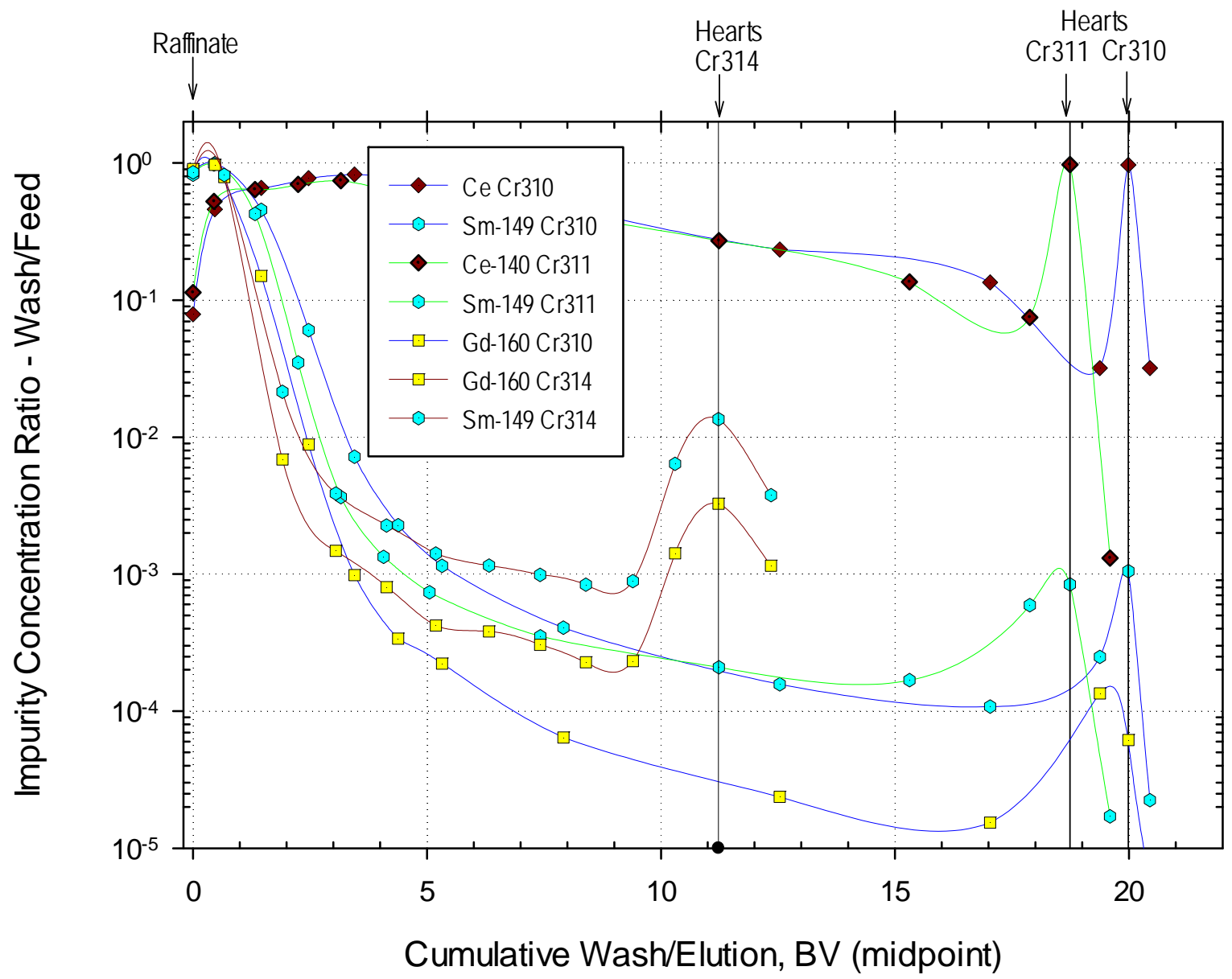

Figure 8. Sm, Gd, and Ce Wash-Elution Profiles. 


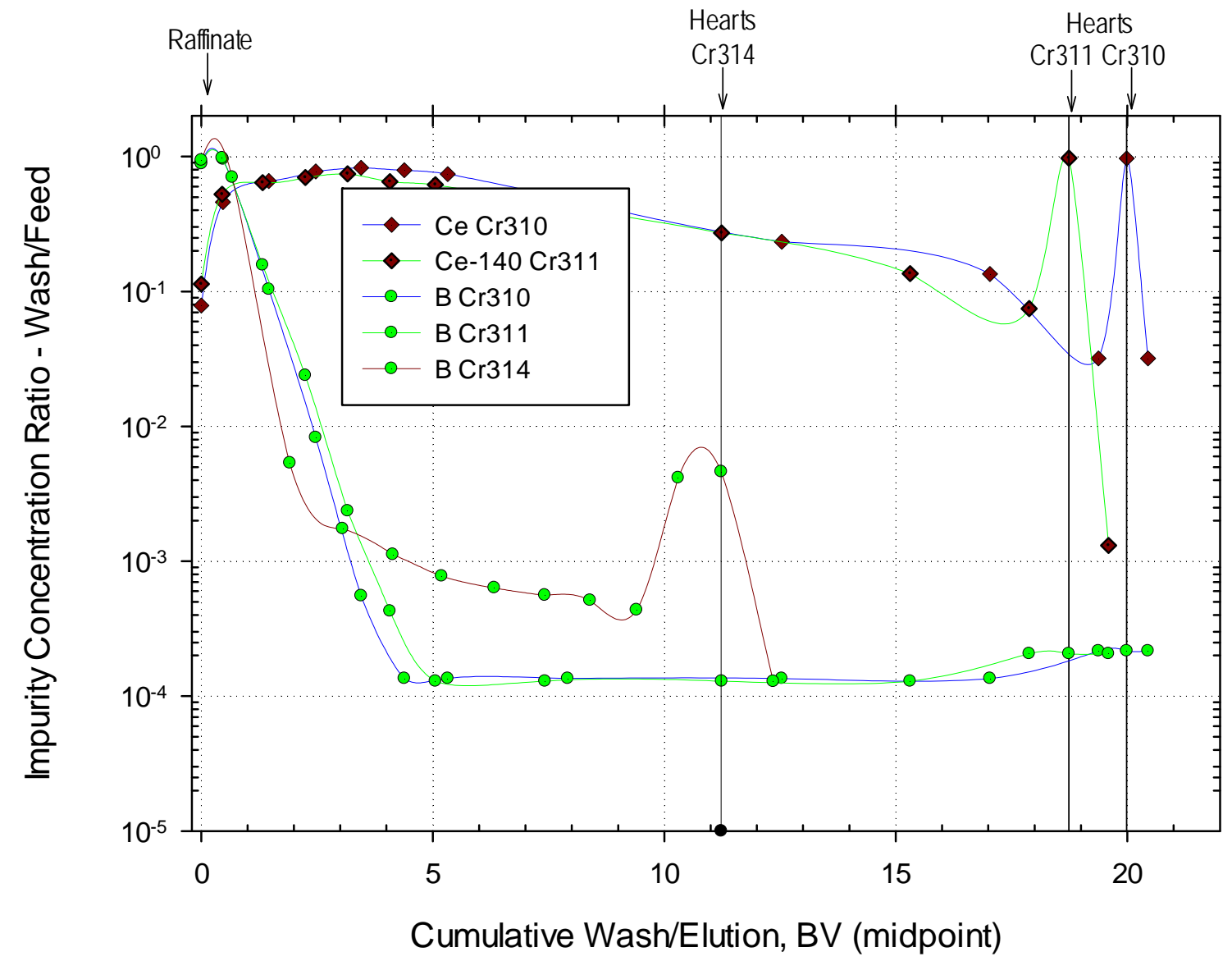

Figure 9. B and Ce Wash-Elution Profiles. 


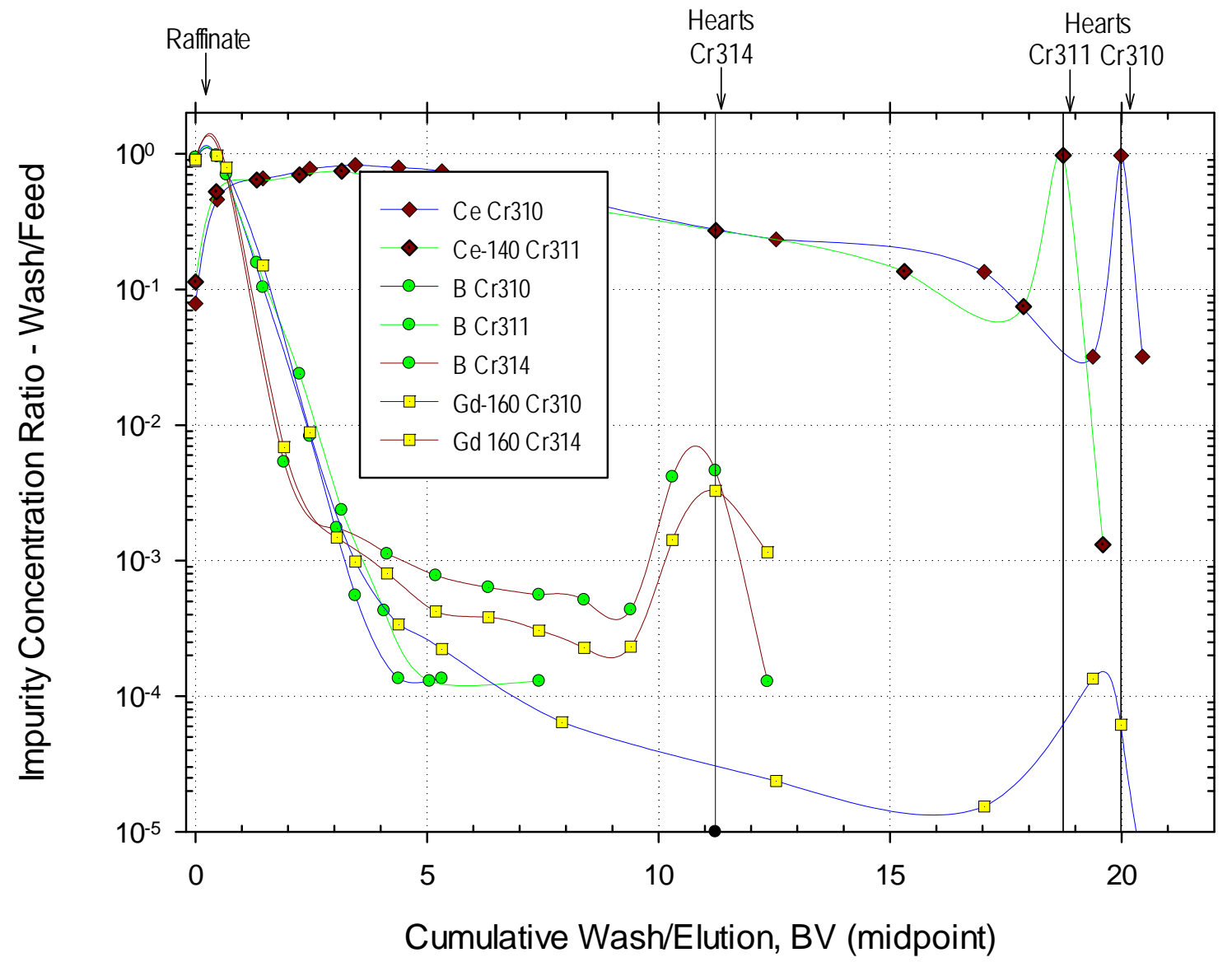

Figure 10. B, Gd, and Ce Wash-Elution Profiles. 


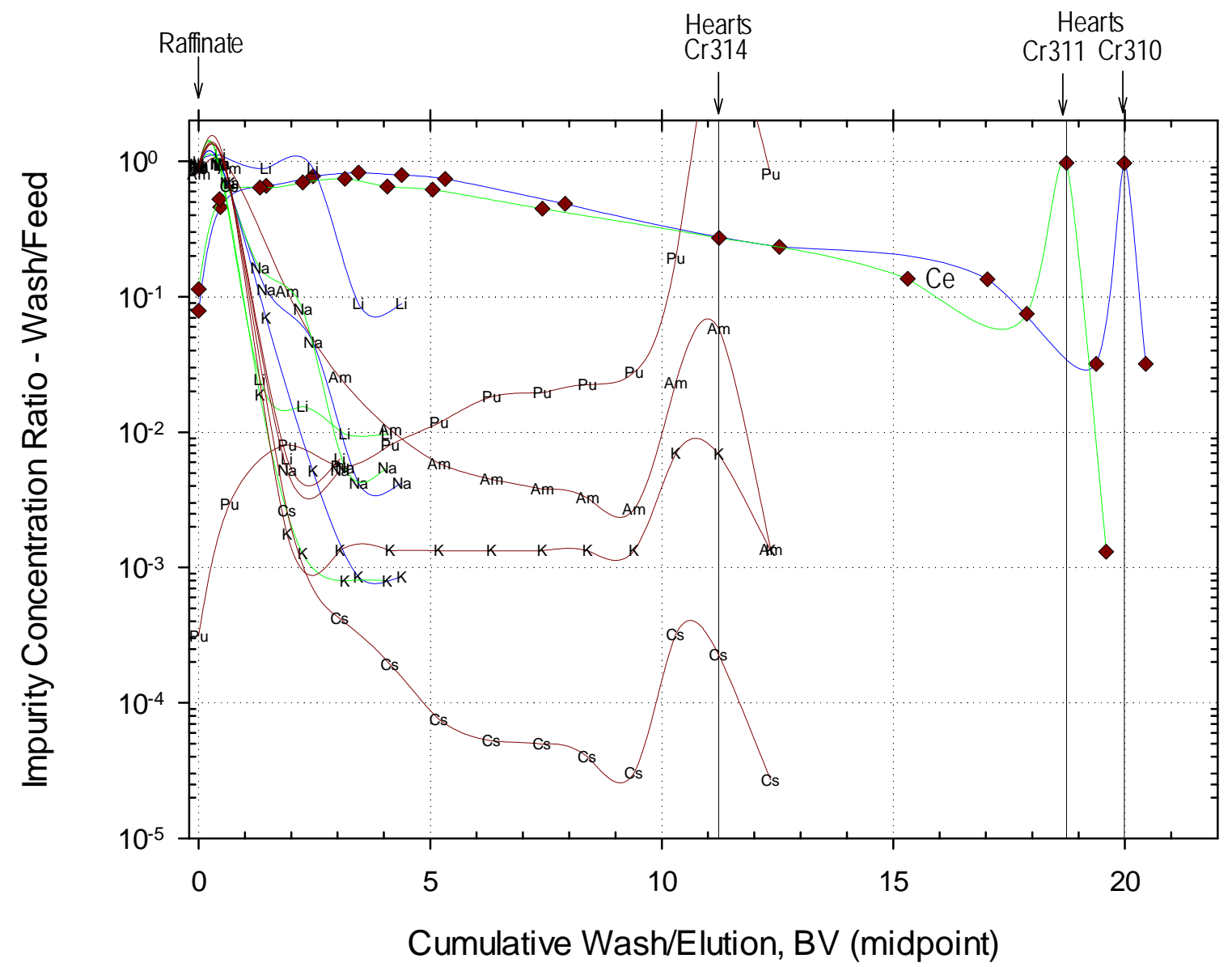

Figure 11. Li, $\mathrm{Na}, \mathrm{K}, \mathrm{Cs}, \mathrm{Ce}, \mathrm{Pu}$, and Am Wash-Elution Profiles. 


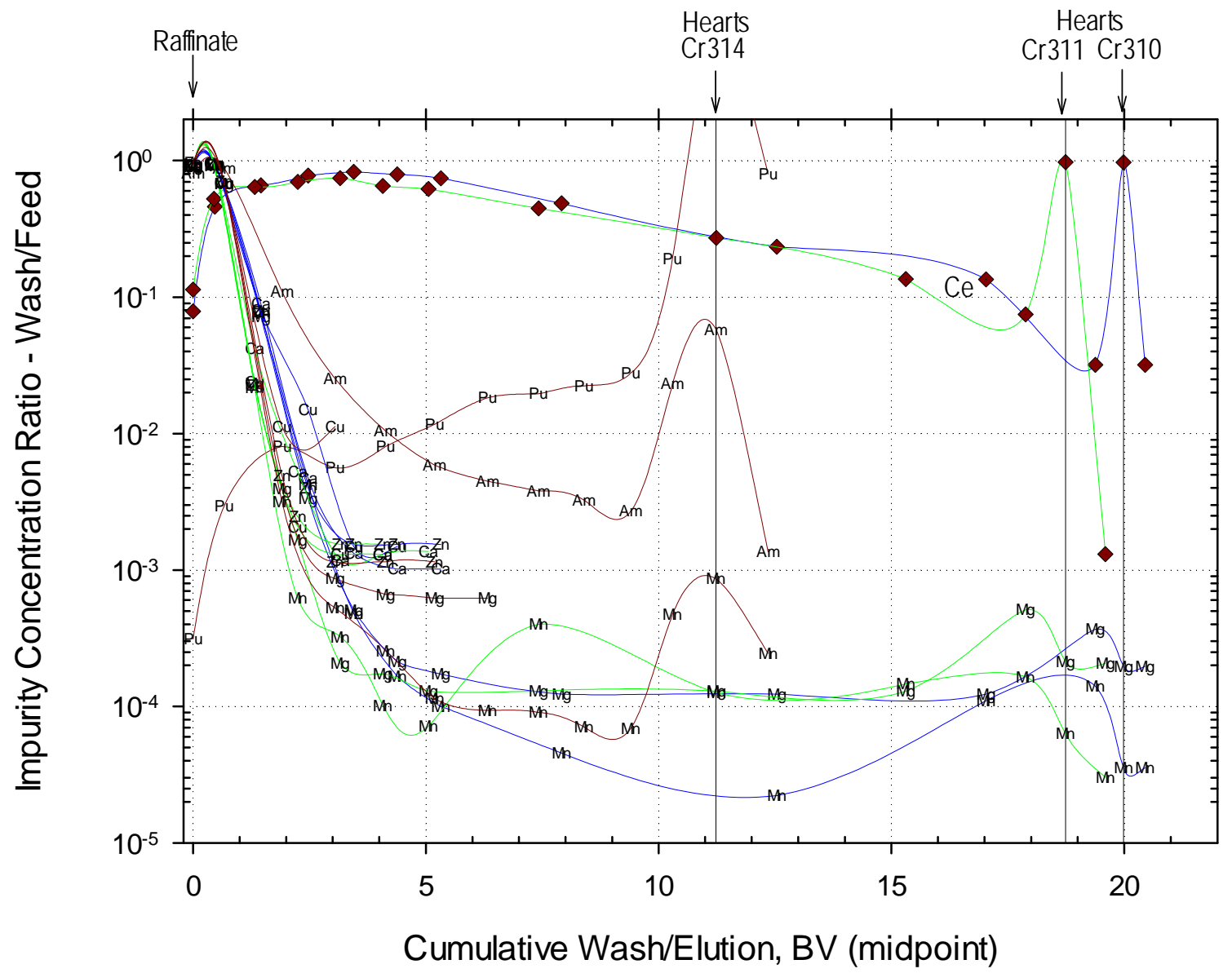

Figure 12. $\mathrm{Ca}, \mathrm{Cu}, \mathrm{Mg}, \mathrm{Mn}, \mathrm{Zn}, \mathrm{Ce}, \mathrm{Pu}$, and $\mathrm{Am}$ Wash-Elution Profiles. 


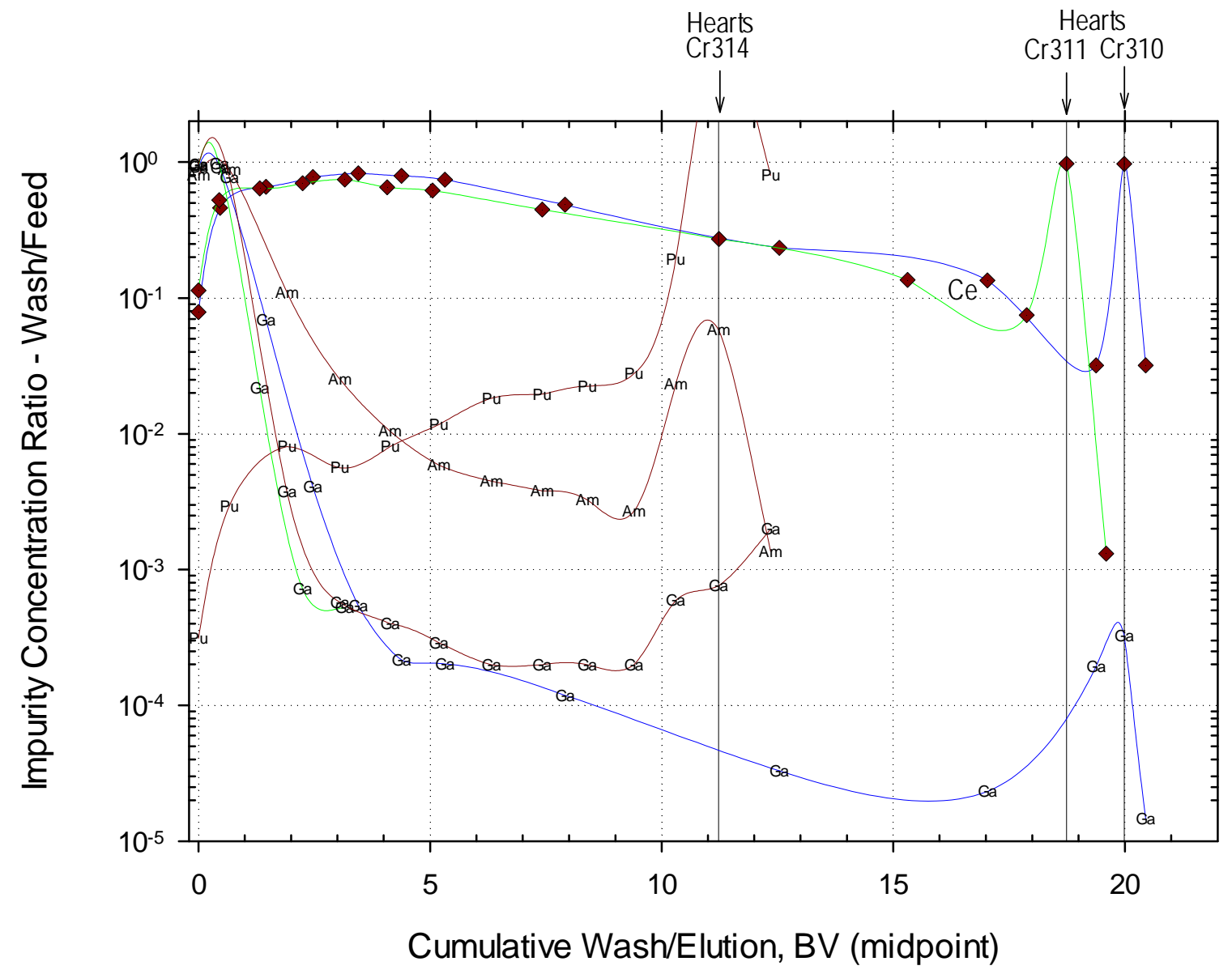

Figure 13. $\mathrm{Ga}, \mathrm{Ce}, \mathrm{Pu}$, and Am Wash-Elution Profiles. 


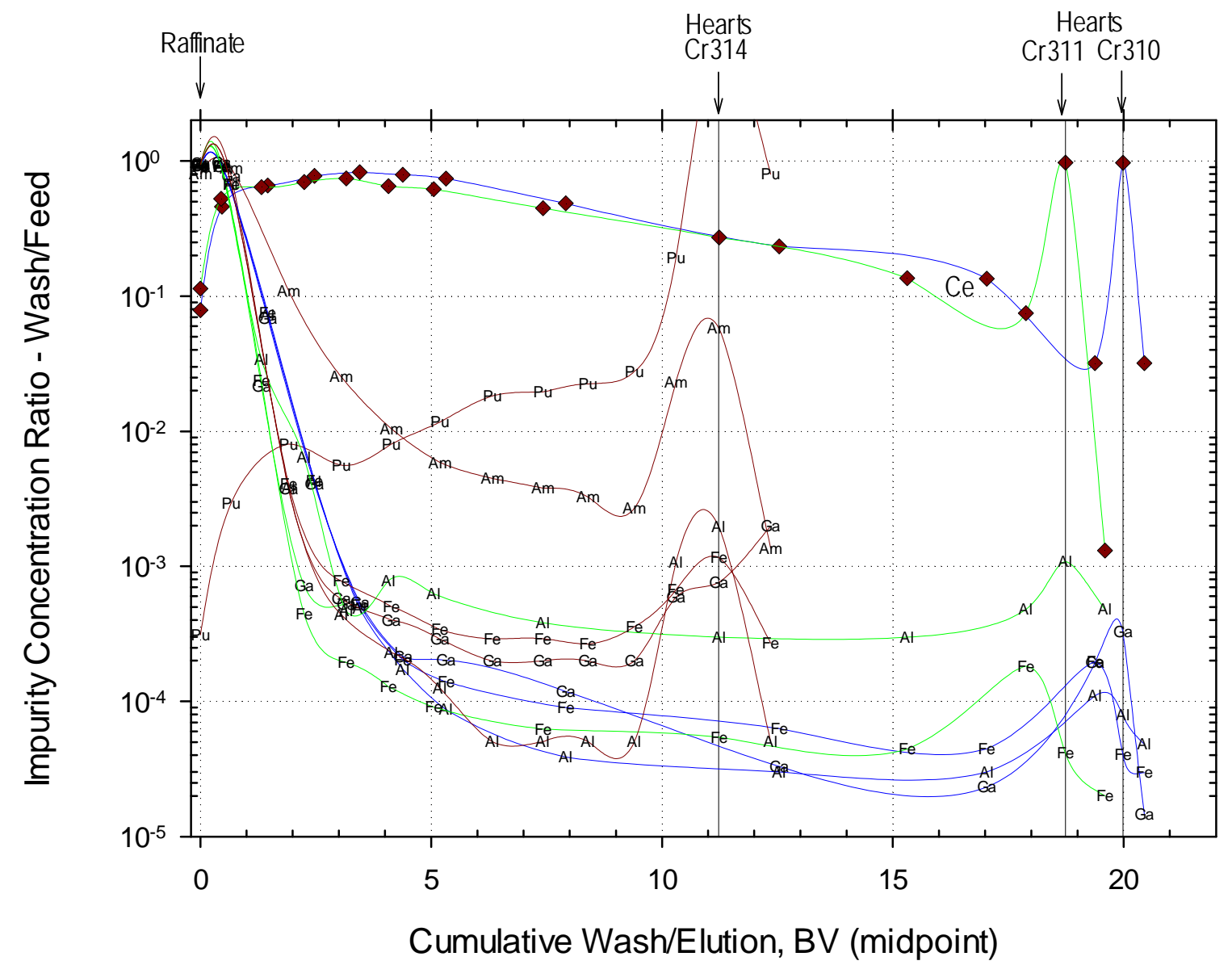

Figure 14. Al, Fe, Ga, Ce, Pu, and Am Wash-Elution Profiles. 


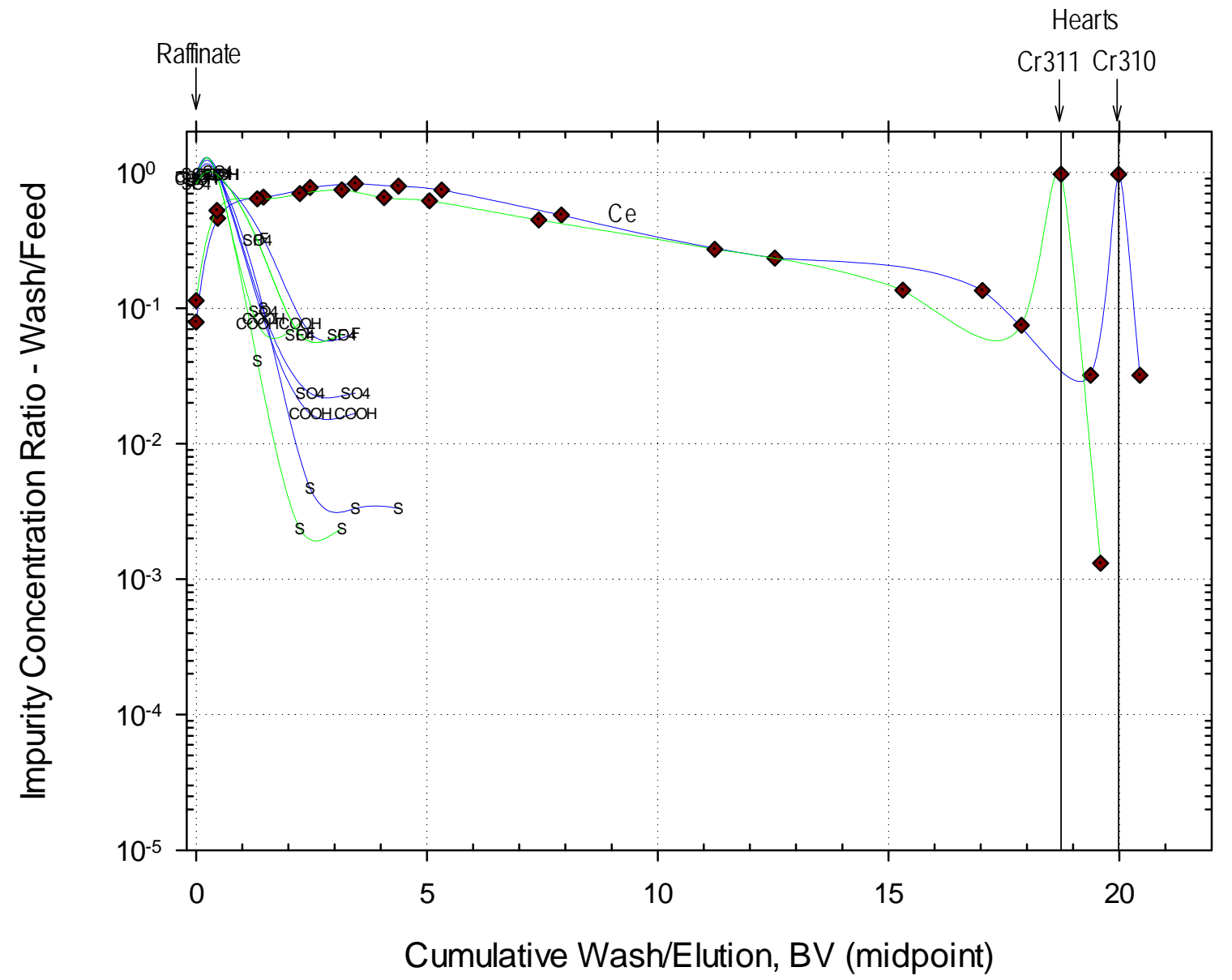

Figure 15. Anions (F, S, SO4, $\mathrm{COOH})$ and Ce Wash-Elution Profiles. 


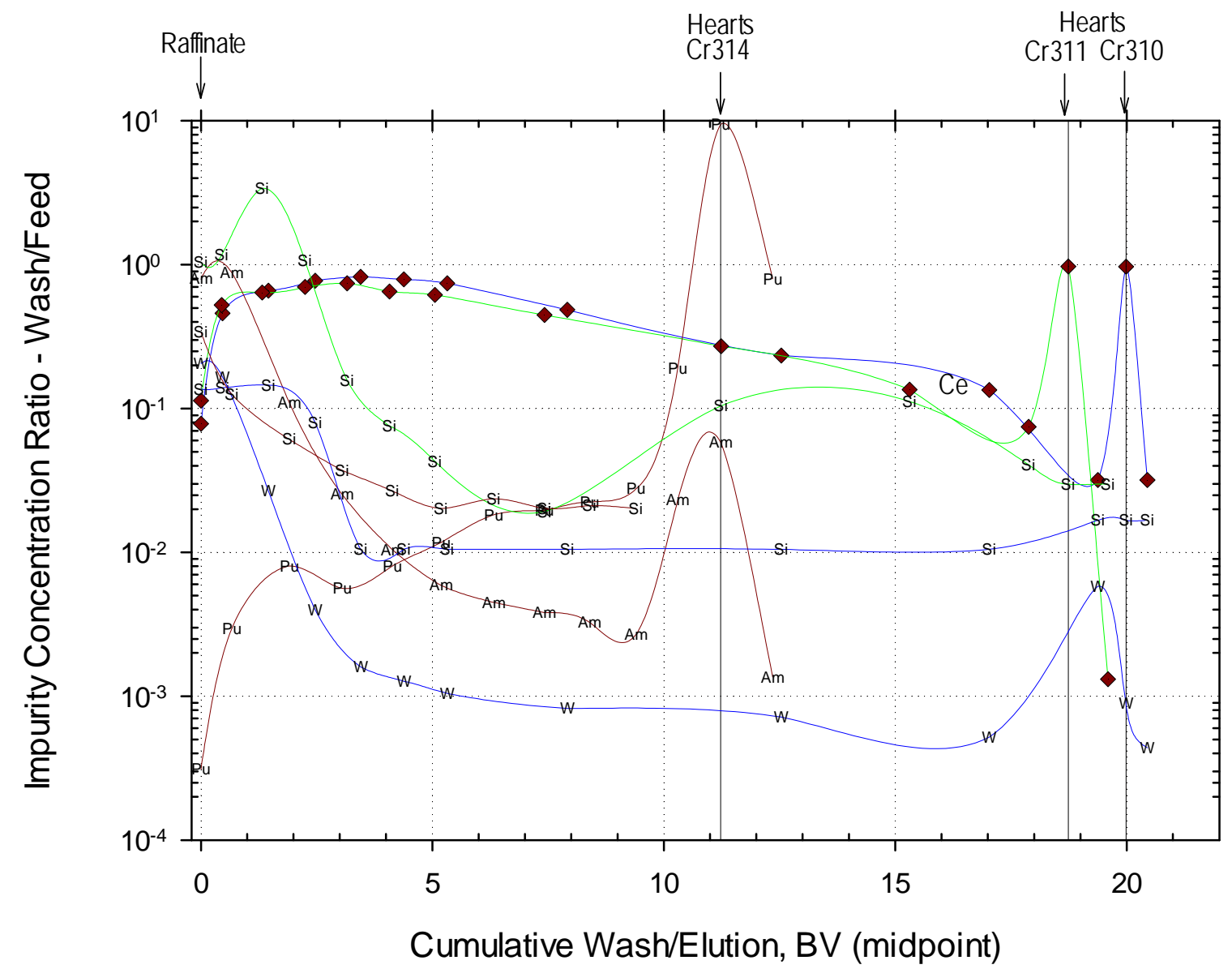

Figure 16. Si, W, and Ce Wash-Elution Profiles. 


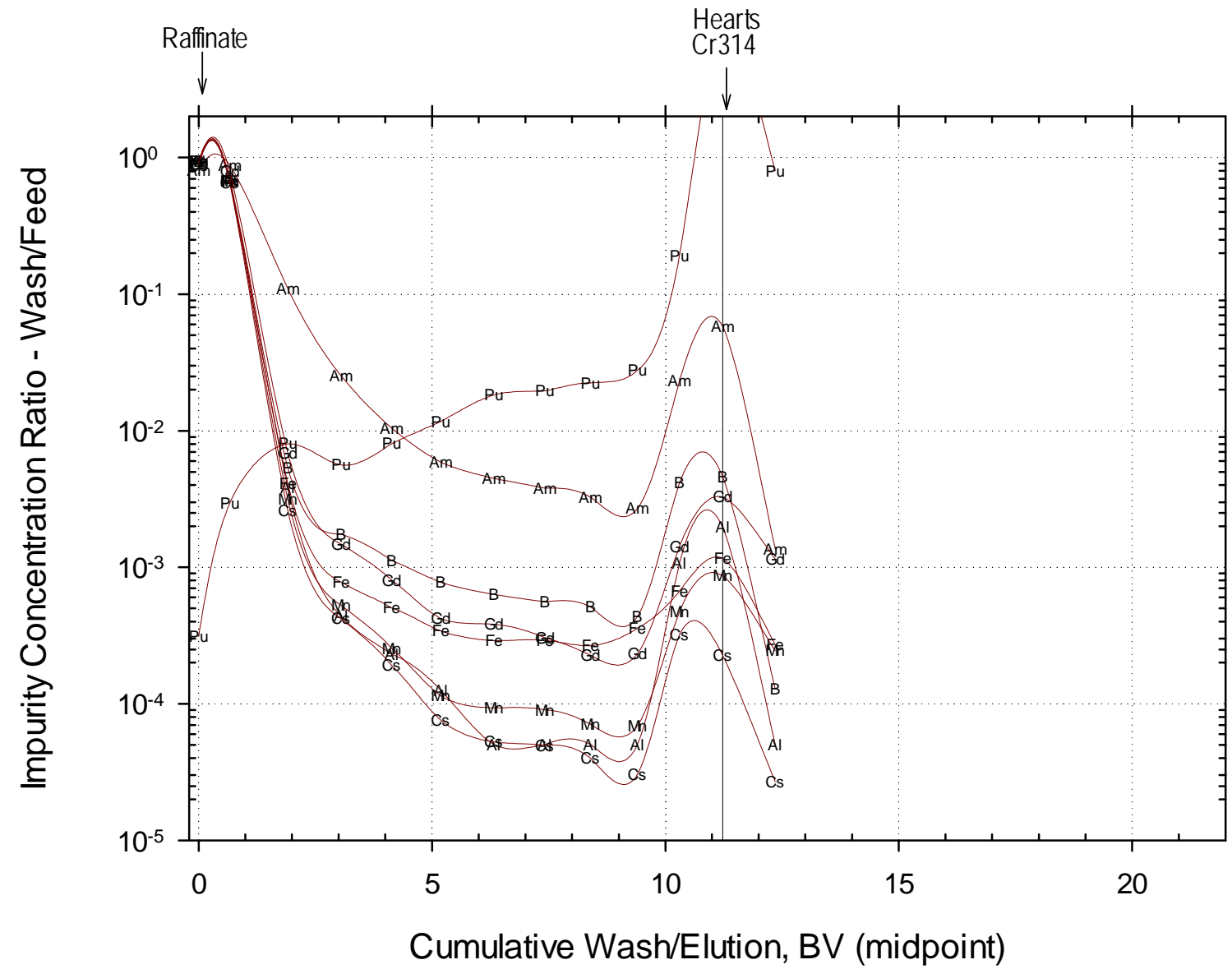

Figure 17. B, Al, Cs, Mn, Gd, Fe, Am, and Pu Wash-Elution Profiles. 
Table 10. Minimum Wash Volumes to Achieve Column A Specification.

\begin{tabular}{ccccc} 
& Limit & \multicolumn{3}{c}{ Wash Required } \\
Element & Col A & Cr310 & Cr311 & Cr314 \\
Al & 500 & BV & BV & BV \\
B & 100 & $3.0^{a}$ & $1.7^{\mathrm{a}}$ & $2.5^{\mathrm{a}}$ \\
$\mathrm{Ca}$ & 500 & 0.9 & $0.6^{\mathrm{a}}$ & $15-20^{\mathrm{c}}$ \\
$\mathrm{Fe}$ & 2000 & 2 & 1.7 & $1.3^{3}$ \\
$\mathrm{Ga}$ & 12000 & 0 & 0 & 0 \\
$\mathrm{Gd}$ & 3 & 8.5 & & $>30^{\mathrm{c}}$ \\
$\mathrm{K}$ & 300 & $3.9^{\mathrm{b}}$ & $2.7^{\mathrm{b}}$ & $2.5^{\mathrm{b}}$ \\
$\mathrm{Li}$ & 400 & $0.0^{\mathrm{a}}$ & $0.9^{\mathrm{a}}$ & $1.3^{\mathrm{a}}$ \\
$\mathrm{Mg}$ & 500 & $0.9^{\mathrm{a}}$ & $0.9^{\mathrm{a}}$ & $1.3^{\mathrm{a}}$ \\
$\mathrm{Mn}$ & 100 & $3.0^{\mathrm{a}}$ & $2.7^{\mathrm{a}}$ & $2.5^{\mathrm{a}}$ \\
$\mathrm{Na}$ & 1000 & $0.9^{\mathrm{a}}$ & $0.9^{\mathrm{a}}$ & $1.3^{\mathrm{a}}$ \\
$\mathrm{S}$ & 250 & $3.9^{\mathrm{b}}$ & $2.7^{\mathrm{b}}$ & $2.5^{\mathrm{b}}$ \\
$\mathrm{Si}$ & 200 & $3.0^{\mathrm{a}}$ & $3.6^{\mathrm{b}}$ & $6.9^{\mathrm{a}}$ \\
$\mathrm{Sm}$ & 2 & 13.5 & 15.5 & $>30^{\mathrm{c}}$ \\
$\mathrm{W}$ & 200 & $0.9^{2}$ & & \\
$\mathrm{Zn}$ & 150 & $2.0^{\mathrm{a}}$ & $0.9^{\mathrm{a}}$ & $1.3^{\mathrm{a}}$
\end{tabular}

Note: Wash values assume entire Displacement volume is discarded.

a Values below instrumental detection limits were treated as real values, so minimum wash values are believed to be lower than calculated

${ }^{b}$ Alternate calculation Method B (see text)

${ }^{\mathrm{C}}$ Estimate based on data extrapolation 
Table 11. Minimum Wash Volumes to Achieve Column B Specification.

\begin{tabular}{|c|c|c|c|c|}
\hline & Limit & \multicolumn{3}{|c|}{ Wash Required } \\
\hline & Col B & Cr310 & Cr311 & Cr314 \\
\hline Element & ug/g Pu & BV & BV & BV \\
\hline Al & 100 & $4.8^{a}$ & $3.6^{a}$ & $3.6^{b}$ \\
\hline B & 1 & $>19.0^{a}$ & $>17.4^{a}$ & $>35^{c}$ \\
\hline $\mathrm{Ca}$ & 150 & 2 & 1.7 & 2.5 \\
\hline $\mathrm{Fe}$ & 500 & 3 & 1.7 & 2.5 \\
\hline $\mathrm{Ga}$ & 0.12 & $>19.0$ & 17.4 & $>9.9$ \\
\hline Gd & 0.5 & $15-19$ & & $>30^{c}$ \\
\hline K & 100 & $3.9 \mathrm{~b}$ & $2.7^{b}$ & $3.6^{b}$ \\
\hline $\mathrm{Li}$ & 100 & $3.0^{a}$ & $0.9^{a}$ & $1.3^{a}$ \\
\hline $\mathrm{Mg}$ & 200 & $2.0^{a}$ & $0.9 a$ & $1.3^{a}$ \\
\hline $\mathrm{Mn}$ & 100 & $3.0^{a}$ & 2.7 & 2.5 \\
\hline $\mathrm{Na}$ & 100 & $3.9^{b}$ & $3.6^{b}$ & $2.5^{b}$ \\
\hline $\mathrm{S}$ & 250 & $3.9^{b}$ & $2.7^{b}$ & $2.5^{b}$ \\
\hline Si & 150 & $6-10^{a}$ & $3.6^{b}$ & $2.5^{b}$ \\
\hline Sm & 2 & 13.5 & 15.5 & $>30^{c}$ \\
\hline W & 100 & 0.9 & & \\
\hline $\mathrm{Zn}$ & 100 & $2.0^{a}$ & $0.9 \mathrm{a}$ & 1.3 \\
\hline
\end{tabular}

Note: Wash values assume entire Displacement volume is discarded.

${ }^{a}$ Values below instrumental detection limits were treated as real values, so minimum wash values are believed to be lower than calculated

${ }^{b}$ Alternate calculation Method B (see text)

${ }^{\mathrm{C}}$ Estimates based on background-corrected data 


\section{Distribution:}
S. D. Fink, 773-A
K. M. Fox, 999-W
B. J. Giddings, 786-5A
C. C. Herman, 999-W
S. L. Marra, 773-A
F. M. Pennebaker, 773-42A
W. R. Wilmarth, 773-A
W. E. Harris, 704-2H
J. B. Schaade, 704-2H
G. J. Zachman, 225-7H
P. B. Andrews, 704-2H
S. J. Howell, 704-3H
M. J. Swain, 703-H
M. J. Lewczyk, 221-H
K. P. Burrows, 704-2H
J. E. Therrell, 704-2H
J. W. Christopher, 704-2H
R. H. Smith, 704-2H
R. R. Livingston, 730-2B
J. L. O'Conner, 704-2H
W. G. Dyer, 704-2H
S. L. Hudlow, 221-H
W. H. Clifton, 704-2H
E. A. Kyser, 773-A
T. S. Rudisill, 773-A
R. A. Pierce, 773-A
C. A. Nash, 773-42A
W. D. King, 773-42A
M. C. Thompson, 773-A
C. M. Gregory, 773-A
D. P. Diprete, 773-A
B. J. Wiedenman, 773-A
T. L. White, 773-A
M. A. Jones, 773-A
S. A. Thomas, 703-46A 